\title{
Biometria de plantas e sementes de fava: contribuições para divergência genética
}

\author{
Biometry of lima bean plants and seeds: contributions to genetic divergence \\ Biometría de plantas y semillas de haba: contribuciones a la divergencia genética
}

Recebido: 18/01/2021 | Revisado: 21/01/2021 | Aceito: 26/01/2021 | Publicado: 02/02/2021

\author{
Daniel Rodrigues Nere \\ ORCID: https://orcid.org/0000-0003-2653-4142 \\ Universidade Federal do Ceará, Brasil \\ E-mail: danielnere@gmail.com \\ Ervino Bleicher \\ ORCID: https://orcid.org/0000-0003-3820-7114 \\ Universidade Federal do Ceará, Brasil \\ E-mail: ervinob@gmail.com \\ Cândida Hermínia Campos de Magalhães Bertini \\ ORCID: https://orcid.org/0000-0003-2949-5660 \\ Universidade Federal do Ceará, Brasil \\ E-mail: candida@ufc.br
}

\begin{abstract}
Resumo
A fava (Phaseolus lunatus) possui uma ampla variabilidade genética. Para explorar este potencial são empregados os descritores da cultura, que são um conjunto de indicações técnicas que auxiliam nos registros das informações das características presente neste material genético. No entanto, algumas informações presentes nos descritores necessitam ser atualizadas e outras adicionadas para que se possa descrever o máximo de características. Assim, objetivou-se com essa pesquisa obter informações sobre os aspectos biométricos de sementes e plantas de fava que possam contribuir para estudos de divergência genética. Nesta pesquisa foram utilizadas 70 variedades de fava e foi dividida em duas etapas, na primeira, realizou-se a caracterização das sementes e na segunda, caracterização da planta, na fase vegetativa e reprodutiva. Aos dados aplicou-se estatística descritiva para obtenção de porcentagem, média, desvio padrão, classes, histogramas, polígonos de frequência e boxplots. Os resultados demonstraram a grande variabilidade genética nas variedades estudadas, as características em sua maioria de importância produtiva apresentaram 9 diferentes classificações. As informações geradas permitem, portanto, contribuições nos estudos de beneficiamento de sementes e grãos, investigação da preferência do consumidor e nas pesquisas de divergência genética, todas associadas à formação de futuras cultivares.
\end{abstract}

Palavras-chave: Phaseolus lunatus; Descritores; Sementes tradicionais.

\begin{abstract}
The lima bean (Phaseolus lunatus) has a wide genetic variability. To exploit this potential, descriptors are used, which are a set of details that help to register the information of the characteristics present in this genetic material. However, some information present in the descriptors needs to be updated and others added in order to describe the maximum characteristics. Thus, this research aimed to obtain information about the biometric aspects of lima bean seeds and plants that can contribute to studies of genetic divergence. The research used 70 lima beans landraces and was divided into two stages. In the first stage the characterization of the seeds and, in the second, characterization of the plant. Both, at the vegetative and reproductive phase, descriptive statistics were applied to the data to obtain percentage, average, standard deviation, classes, histograms, frequency polygons and boxplots. The results demonstrated the great genetic variability in the studied landraces. The characteristics in their majority of productive importance presented 9 different classifications. The information generated, therefore, allows contributions to studies on the improvement of seeds and grains, investigation of consumer preference and research on genetic divergence, all associated with the formation of future cultivars.
\end{abstract}

Keywords: Phaseolus lunatus; Descriptors; Landraces.

\section{Resumen}

La haba (Phaseolus lunatus) tiene una amplia variabilidad genética. Para explotar este potencial se utilizan descriptores de cultivo, que son un conjunto de indicaciones técnicas que ayudan a registrar la información de las características presentes en este material genético. Sin embargo, es necesario actualizar alguna información presente en los descriptores y añadir otras para que se pueda describir al máximo las características. Así, el objetivo de esta investigación fue obtener información sobre los aspectos biométricos de semillas y plantas de haba que puedan contribuir a los estudios de divergencia genética. En esta investigación, se utilizaron 70 variedades de haba y se dividió en dos etapas, en la primera, se realizó la caracterización de las semillas y en la segunda, caracterización de la planta, en la fase vegetativa y 
reproductiva. Se aplicó estadística descriptiva a los datos para obtener porcentaje, media, desviación estándar, clases, histogramas, polígonos de frecuencia y diagramas de caja. Los resultados demostraron la gran variabilidad genética en las variedades estudiadas, las características en su mayoría de importancia productiva presentaron 9 clasificaciones diferentes. Las informaciones generadas permiten, por tanto, realizar aportes a estudios de mejoramiento de semillas y granos, investigación de la preferencia del consumidor e en las investigaciones sobre divergencia genética, todo asociado a la formación de futuros cultivares.

Palabras clave: Phaseolus lunatus; Descriptores; Semillas tradicionales.

\section{Introdução}

A fava (Phaseolus lunatus L.) está entre as quatros espécies do gênero Phaseolus que vem sendo explorada e produzida mundialmente. O seu consumo não se restringe apenas a alimentação humana na forma de grãos verdes e secos, mas seus ramos e folhas também podem ser utilizados na alimentação animal. Além disso, ela pode servir como fonte de matéria orgânica (adubo verde) para recuperação de solos pobres ou esgotados pelo uso intensivo (Azevedo et al., 2003; Franco e Araújo 2003; Pegado et al., 2008; Santos et al., 2002; Vieira, 1992).

Contudo, pode-se dizer que o potencial da fava ainda é pouco explorado. Isto sugere a necessidade de realização de novas pesquisas que contribuam para a seleção de materiais genéticos mais produtivos e indicados a cada região e favoreçam o desenvolvimento de novas tecnologias que ajudem a incrementar a modernização da produção.

A partir de dos estudos de caracterização morfológica se torna possível fornecer uma série de dados que permitem identificar cada genótipo e estudar a variabilidade genética, em busca de plantas com boas respostas à produtividade e adaptadas às diferentes condições ambientais (Santos et al., 2002; Ramos \& Queiróz,1999). Os referidos estudos são realizados com base na lista de indicações técnicas sobre descritores e estádios fenológicos dos descritores da cultura, fornecidos por especialistas de todo mundo sobre registros de dados de Phaseolus lunatus (IBPGR, 1982).

Em 1982, o Centro Internacional para os Recursos Genéticos Vegetais (IBPGR) publicou o estudo, Descriptors for Lima Bean, que posteriormente foi traduzido e adaptado pelo International Plant Genetic Resources Institute (IPGRI), para que os países africanos de língua oficial Portuguesa pudessem implementar e consolidar a conservação, documentação e utilização sustentáveis dos recursos genéticos de P. lunatus (IPGRI, 2001).

Este sistema de descritores é amplamente utilizado no mundo como base para estudos de caracterização das plantas e sementes das variedades de fava (Akande \& Balogun, 2007; López-Alcocer et al., 2016; Vera et al., 2015), sendo que muitos pesquisadores usam as informações dos descritores integrados as regras de análises de sementes vigentes em seus países (Advíncula et al., 2015; Barreiro Neto et al., 2015; Frazão et al., 2010; Guimarães et al., 2007; Nobre et al., 2012; Silva et al., 2015).

Entretanto, algumas informações precisarão ser implementadas e outras adicionadas ao sistema de descritores para ajudar nos programas de melhoramento e, uma das formas é por meio dos estudos da biometria de sementes e plantas, em que as informações da variabilidade genética podem ser detectadas dentro de populações de uma mesma espécie, além de suas relações com os fatores ambientais (Gonçalves et al., 2013; Macedo et al., 2009).

Deste modo, a pesquisa objetiva fornecer informações sobre os aspectos biométricos de sementes e plantas de fava (Phaseolus lunatus) que possam contribuir para estudos de caracterização e divergência genética.

\section{Metodologia}

\section{Origem das variedades}

As sementes das variedades de favas foram coletadas nas lavouras de agricultores, mercados, mercearias e em feiras livres de municípios do semiárido nordestino e foram encaminhadas para o Laboratório de Análise de Sementes (LAS) do Instituto Federal de Educação, Ciência e Tecnologia do Ceará - Campus Umirim, em Umirim, CE, onde receberam a 
nomenclatura utilizada popularmente e, posteriormente, o número de acesso do banco de germoplasma (Tabela 1).

Tabela 1 - Identificação, denominação e origem dos 70 genótipos de favas coletados na região Nordeste, Brasil.

\begin{tabular}{|c|c|c|}
\hline Acesso & Denominação & Município-Estado (Origem) \\
\hline IFCE-004 & Raio da Lua & Farias Brito $-\mathrm{CE}$ \\
\hline IFCE-006 & Fava Ireu & Farias Brito - CE \\
\hline IFCE-010 & Fava Gigante & Farias Brito - CE \\
\hline IFCE-012 & Fava Carmelita NB & Farias Brito - CE \\
\hline IFCE-014 & Fava dos Oitis & Farias Brito - CE \\
\hline IFCE-015 & Fava Branca Carás & Farias Brito - CE \\
\hline IFCE-016 & Fava do Araticum & Farias Brito $-\mathrm{CE}$ \\
\hline IFCE-017 & Fava Raio de Sol Qui & Farias Brito $-\mathrm{CE}$ \\
\hline IFCE-018 & Fava Branca Contendas & Farias Brito - CE \\
\hline IFCE-019 & Fava Branca Barrocas & Farias Brito $-\mathrm{CE}$ \\
\hline IFCE-020 & Fava de Zé de Júlio & Farias Brito - CE \\
\hline IFCE-021 & Fava Branca UM1 & Umirim - CE \\
\hline IFCE-022 & Fava Branca UM2 & Umirim - CE \\
\hline IFCE-024 & Fava Coquinho Laranja & Farias Brito - CE \\
\hline IFCE-025 & Fava dos Recantos & Farias Brito - CE \\
\hline IFCE-026 & Fava Raio de Sol LS & Farias Brito - CE \\
\hline IFCE-028 & Fava Olho Pintado & Farias Brito - CE \\
\hline IFCE-029 & Fava dos Ferreiras & Farias Brito - CE \\
\hline IFCE-030 & Fava Branca & Farias Brito - CE \\
\hline IFCE-032 & Fava Raio de Sol CT1 & Farias Brito - CE \\
\hline IFCE-036 & Fava Branca & Uruburetama-CE \\
\hline IFCE-037 & Fava Branca SLC & São Luís do Curu - CE \\
\hline IFCE-038 & Fava Mulatinha & Acopiara - CE \\
\hline IFCE-039 & Fava Mulatinha & Senador Pompeu - CE \\
\hline IFCE-040 & Fava Branca & Caririaçu - CE \\
\hline IFCE-041 & Fava Belinha & Caririaçu - CE \\
\hline IFCE-043 & Fava Raio do Sol 1 & Caririaçu - CE \\
\hline IFCE-044 & Fava Lavandeira & Caririaçu $-\mathrm{CE}$ \\
\hline IFCE-046 & Fava Raio do Sol CT2 & Farias Brito - CE \\
\hline IFCE-047 & Fava Branca & Mombaça - CE \\
\hline IFCE-048 & Fava Mulatinha & Mombaça - CE \\
\hline IFCE-049 & Fava Queiroga & Mombaça - CE \\
\hline IFCE-050 & Fava Raio de Sol & Acopiara - CE \\
\hline IFCE-051 & Fava Branca & Acopiara - CE \\
\hline IFCE-052 & Fava Balinha & Acopiara - CE \\
\hline IFCE-053 & Fava Graúda & Farias Brito - CE \\
\hline IFCE-054 & Fava Olho Pintado & Mombaça - CE \\
\hline
\end{tabular}




\begin{tabular}{|c|c|c|}
\hline IFCE-055 & Fava Raio do Sol QC 2 & Farias Brito - CE \\
\hline IFCE-056 & Fava Lavadeira & Farias Brito - CE \\
\hline IFCE-057 & Fava Mulatinha & Juazeiro do Norte - CE \\
\hline IFCE-059 & Fava Gostosinha & Juazeiro do Norte - CE \\
\hline IFCE-060 & Fava Branca & Barro - CE \\
\hline IFCE-061 & Fava Branca & Várzea Alegre - CE \\
\hline IFCE-062 & Fava Preta & Araripe - CE \\
\hline IFCE-063 & Fava Branca CT & Farias Brito $-\mathrm{CE}$ \\
\hline IFCE-064 & Fava Branca & Crato -CE \\
\hline IFCE-065 & Fava Raio do Sol & Várzea Alegre - CE \\
\hline IFCE-066 & Fava Coquinho Laranja & Icó - CE \\
\hline IFCE-082 & Fava Branca & Catolé do Rocha - PB \\
\hline IFCE-083 & Fava Orelha de Vó & Remígio - PB \\
\hline IFCE-084 & Fava Branca & São Miguel - RN \\
\hline IFCE-085 & Fava Manteiga & Catolé do Rocha - PB \\
\hline IFCE-086 & Fava Branca de Moita & Remígio - PB \\
\hline IFCE-087 & Fava Carolaine & Areia - PB \\
\hline IFCE-088 & Fava Branca & Remígio - PB \\
\hline IFCE-089 & Fava Ligeirinha & Belém do Brejo da Cruz - PB \\
\hline IFCE-090 & Fava Cara Larga & Remígio - PB \\
\hline IFCE-091 & Fava Orelha de Vó & Catolé do Rocha - PB \\
\hline IFCE-092 & Fava Mororó & Areia - PB \\
\hline IFCE-093 & Fava do Sítio Coqueiro & Itapipoca - CE \\
\hline IFCE-095 & Fava Serrota UM3 & Umirim - CE \\
\hline IFCE-101 & Fava da Serra Jatobá 1 & Jardim $-\mathrm{CE}$ \\
\hline IFCE-102 & Fava da Serra Jatobá 2 & Jardim $-\mathrm{CE}$ \\
\hline IFCE-103 & Fava da Serra Jatobá 3 & Jardim $-\mathrm{CE}$ \\
\hline IFCE-104 & Fava da Serra Jatobá 4 & Jardim $-\mathrm{CE}$ \\
\hline IFCE-108 & Fava da Serra Jatobá 8 & Jardim $-\mathrm{CE}$ \\
\hline IFCE-109 & Fava da Serra Jatobá 9 & Jardim - CE \\
\hline IFCE-110 & Fava da Serra Jatobá 10 & Jardim $-\mathrm{CE}$ \\
\hline IFCE-112 & Branca de Mombaça & Mombaça - CE \\
\hline IFCE-114 & Fava dos Oliveiras & Itapipoca - CE \\
\hline
\end{tabular}

Fonte: Autores (2021).

\section{Caracterização das sementes}

Para realização das análises, foram selecionadas sementes de cada um dos genótipos para composição dos lotes, sendo eliminadas aquelas quebradas, ocas ou com ataque de pragas. Dos lotes formados por mil sementes, foram retiradas as amostras para as análises de peso, comprimento, largura, espessura e cor.

$\mathrm{Na}$ avaliação das características morfológicas da semente - comprimento, largura e espessura - utilizou-se um paquímetro digital (precisão 0,01 mm) em 100 sementes de cada variedade (BRASIL, 2009). Com as medidas, as sementes ainda 
foram classificadas quanto à forma e o perfil, a forma em função da relação entre comprimento/largura e o perfil, em função da relação espessura/largura (Vilhordo et al., 1996). Para o peso, oito amostras de 100 sementes foram retiradas do lote de 1000 sementes, estas seguiram para pesagem em balança analítica com precisão 0,0001g.

Para determinação da cor do tegumento das sementes, as informações da caderneta de identificação de cores de solos de Munsell (1994) foram organizadas e traduzidas conforme Santos et al. (2005) de modo que possam ser utilizadas na caracterização morfológica e contribuam para a divergência genética (Tabela 2). Inicialmente foi realizada a comparação da cor do tegumento da semente com os padrões constantes na carta de Munsell, que se expressa em três parâmetros, matiz, valor e croma (exemplo: 2.5Y 2.5/1). A matiz refere-se ao espectro dominante da cor, o valor a sua tonalidade e o croma a pureza relativa ou saturação. Com a notação da cor, consultou-se na Coluna 1 da Tabela 2 a mesma referência, obtendo-se assim a nomenclatura na Coluna 2 e os valores para análise discreta na Coluna 3 (no caso desta pesquisa) e valores para análise contínua na Coluna 4.

Tabela 2 - Classificação da cor do tegumento das sementes de 70 variedades de Phaseolus lunatus. Umirim-CE, 2017.

\begin{tabular}{|c|c|c|c|}
\hline Cor de Munsell $^{1}$ & Tradução da Cor ${ }^{2}$ & Classes $^{3}$ & Subclasses $^{4}$ \\
\hline $\begin{array}{l}2.5 \mathrm{Y} 8 / 1,7.5 \mathrm{R} 8 / 1,5 \mathrm{Y} 8 / 1, \\
5 \mathrm{YR} 8 / 1,10 \mathrm{YR} 8 / 1,2.5 \mathrm{YR} \\
8 / 1, \quad 10 \mathrm{R} \text { 8/1, GLEY1 8/, } \\
\text { 7.5YR 8/1 }\end{array}$ & Branco & 1 & 1.0 \\
\hline $\begin{array}{l}2.5 \mathrm{YR} 8 / 2,5 \mathrm{YR} 8 / 2,10 \mathrm{R} 8 / 2, \\
7.5 \mathrm{YR} 8 / 2,2.5 \mathrm{Y} 4 / 1\end{array}$ & Branca Rosado & 1 & $1 . .1$ \\
\hline $\begin{array}{l}\text { 10R 8/3, 10R 8/4, 2.5YR 8/3, } \\
2.5 \mathrm{YR} 8 / 4,5 \mathrm{YR} \text { 7/3, 5YR } \\
7 / 4,5 \mathrm{YR} \quad 8 / 3,5 \mathrm{YR} \quad 8 / 4, \\
7.5 \mathrm{YR} 7 / 3,7.5 \mathrm{YR} 7 / 4,7.5 \mathrm{YR} \\
8 / 3,7.5 \mathrm{YR} 8 / 4\end{array}$ & Rosado & 2 & 2.0 \\
\hline $7.5 \mathrm{R} 8 / 2,7.5 \mathrm{R} 8 / 3,7.5 \mathrm{R} 8 / 4$ & Rosa Claro & 2 & 2.1 \\
\hline $\begin{array}{l}2.5 \mathrm{Y} 7 / 6,2.5 \mathrm{Y} 7 / 8,2.5 \mathrm{Y} 8 / 6 \\
2.5 \mathrm{Y} 8 / 8,10 \mathrm{YR} 7 / 6,10 \mathrm{YR} \\
7 / 8,10 \mathrm{YR} 8 / 6,10 \mathrm{YR} 8 / 8,5 \mathrm{Y} \\
7 / 6,5 \mathrm{Y} 7 / 8,5 \mathrm{Y} 8 / 6,5 \mathrm{Y} 8 / 8\end{array}$ & Amarelo & 3 & 3.0 \\
\hline $\begin{array}{l}2.5 \mathrm{Y} 7 / 3,2.5 \mathrm{Y} 7 / 4,2.5 \mathrm{Y} 8 / 2 \\
2.5 \mathrm{Y} 8 / 3,2.5 \mathrm{Y} 8 / 4,5 \mathrm{Y} 7 / 3 \\
5 \mathrm{Y} 7 / 4,5 \mathrm{Y} 8 / 2,5 \mathrm{Y} 8 / 3,5 \mathrm{Y} \\
8 / 4\end{array}$ & Amarelo claro acinzentado & 3 & 3.1 \\
\hline $\begin{array}{l}\text { 5YR 6/6, 5YR 6/8, 5YR 7/6, } \\
\text { 5YR 7/8, 7.5YR 6/6, 7.5YR } \\
\text { 6/8, 7.5YR 7/6, 7.5YR 7/8, } \\
\text { 7.5YR 8/6 }\end{array}$ & Amarelo avermelhado & 3 & 3.2 \\
\hline 10YR 6/6, 10YR 6/8 & Amarelo brunado & 3 & 3.3 \\
\hline $\begin{array}{l}2.5 \mathrm{Y} 6 / 6,2.5 \mathrm{Y} 6 / 8,5 \mathrm{Y} 6 / 6 \\
5 \mathrm{Y} 6 / 8\end{array}$ & Amarelo oliváceo & 3 & 3.4 \\
\hline
\end{tabular}


2.5YR 4/6, 2.5YR 4/8, 2.5YR

$5 / 6,2.5 \mathrm{YR} 5 / 7,10 \mathrm{R} 4 / 6,10 \mathrm{R}$

$4 / 8,10 \mathrm{R} 5 / 6,10 \mathrm{R} 5 / 8,7.5 \mathrm{R}$

$4 / 6,7.5 \mathrm{R} 4 / 8,7.5 \mathrm{R} 5 / 6,7.5 \mathrm{R}$

$5 / 8$

5YR 5/6, 5YR 5/8, 5YR 4/6 Vermelho amarelado

4

2.5YR 6/6, 2.5YR 6/8, 2.5YR

7/6, 2.5YR 7/8，7.5R 6/6,

7.5R 6/7, 7.5R 7/6, 7.5R 7/8,

10R 6/6, 10R 6/8, 10R 7/6,

10R $7 / 8$

2.5YR 6/2, 2.5YR 7/2, 7.5R

$6 / 2,7.5 \mathrm{R} 6 / 3,7.5 \mathrm{R} 6 / 4,7.5 \mathrm{R}$

7/2, 7.5R 7/3, 7.5R 7/4, 10R

6/2, 10R 6/3, 10R 6/4, 10R

7/2, 10R 7/3, 10R 7/4

2.5YR 4/2, 2.5YR 5/2, 5YR

4/6, 5YR 5/6, 5YR 5/8, 7.5R

4/2, 7.5R 4/3, 7.5R 4/4, 7.5R

5/2, 7.5R 5/3, 7.5R 5/4, 10R

4/2, 10R 4/3, 10R 4/4,10R

$5 / 2,10 \mathrm{R} 5 / 3,10 \mathrm{R} 5 / 4$

\begin{tabular}{lccc}
\hline $\begin{array}{l}\text { 7.5R 3/2, 7.5R 3/3, 7.5R 3/4, } \\
\text { 10R 3/2, 10R 3/3, 10R 3/4 }\end{array}$ & Vermelho escuro acinzentado & 4.5 \\
\hline $\begin{array}{l}\text { 2.5YR 2.5/2, 10R 2.5/2, 7.5R } \\
\text { 2.5/2, 7.5R 2.5/3, 7.5R 2.5/4 }\end{array}$ & Vermelho muito escuro acinzenta & 4 & 4.6 \\
\hline $\begin{array}{l}2.5 \mathrm{YR} 3 / 6,7.5 \mathrm{R} 3 / 6,7.5 \mathrm{R} \\
\text { 3/8, 10R 3/6 }\end{array}$ & Vermelho escuro & 4 & 4.7 \\
\hline
\end{tabular}

GLEY1 2.5/2, GLEY1 3/2,

7.5YR 4/2, 7.5YR 4/3, 7.5YR

4/4, 7.5YR 5/2, 7.5YR 5/3,

Bruno

5

5.0

7.5YR 5/4, 10YR 4/3, 10YR

$5 / 3$

\begin{tabular}{lccc}
\hline 7.5YR 6/3, 7.5YR 6/4 & Bruno claro & 5 & 5.1 \\
\hline 10YR 6/3 & Bruno claro acinzentando & 5 & 5.2 \\
\hline 10YR 7/3, 10YR 7/4, 10YR & Bruno muito claro acinzentado & 5 & 5.3 \\
$8 / 2,10$ YR 8/3, 10YR 8/4 & Bruno acinzentado & 5.4 \\
\hline $2.5 Y$ 5/2, 10YR 5/2 & Bruno acinzentado escuro & 5 \\
\hline 2.5Y 4/2, 10YR 4/2 & Bruno acinzentado muito escuro & 5 & 5.6 \\
\hline GLEY2 3/1, GLEY1 & $3 / 1$, & 5.5
\end{tabular}




\begin{tabular}{|c|c|c|c|}
\hline $2.5 \mathrm{Y} 3 / 2$ & & & \\
\hline $\begin{array}{l}\text { 10YR 4/1,7.5YR 3/2, 7.5YR } \\
3 / 3,7.5 \text { YR 3/4, 10YR } 3 / 3\end{array}$ & Bruno escuro & 5 & 5.7 \\
\hline $\begin{array}{l}7.5 \text { YR } 2.5 / 2,7.5 \text { YR } 2.5 / 3, \\
\text { 10YR 3/1, 5Y 3/1, 5YR 4/2 }\end{array}$ & Bruno muito escuro & 5 & 5.8 \\
\hline $10 \mathrm{YR} 3 / 2$ & Bruno muito escuro acinzentado & 5 & 5.9 \\
\hline $\begin{array}{l}7.5 \mathrm{YR} 4 / 6,7.5 \mathrm{YR} 5 / 6,7.5 \mathrm{YR} \\
5 / 8\end{array}$ & Bruno forte & 6 & 6.0 \\
\hline $\begin{array}{llll}10 \mathrm{YR} & 2 / 2, & 7.5 \mathrm{YR} & 2.5 / 2, \\
7.5 \mathrm{YR} & 2.5 / 3 & & \end{array}$ & Bruno muito forte & 6 & 6.1 \\
\hline $10 \mathrm{YR} 6 / 4,2.5$ Y $6 / 3,2.5$ Y $6 / 4$ & Bruno amarelado claro & 6 & 6.2 \\
\hline $\begin{array}{l}\text { 10YR 3/4, 10YR 3/6, 10YR } \\
4 / 4,10 \mathrm{YR} 4 / 6\end{array}$ & Bruno amarelada escura & 6 & 6.3 \\
\hline $\begin{array}{l}2.5 \mathrm{YR} 4 / 3,2.5 \mathrm{YR} 4 / 4,2.5 \mathrm{YR} \\
5 / 3,2.5 \mathrm{YR} 5 / 4,5 \mathrm{YR} 4 / 3, \\
5 \mathrm{YR} 4 / 4,5 \mathrm{YR} 5 / 3,5 \mathrm{YR} 5 / 4, \\
2.5 \mathrm{YR} 4 / 3,2.5 \mathrm{YR} 4 / 4,2.5 \mathrm{YR} \\
5 / 3,2.5 \mathrm{YR} 5 / 4,5 \mathrm{YR} 4 / 3, \\
5 \mathrm{YR} 4 / 4,5 \mathrm{YR} 5 / 3,5 \mathrm{YR} 5 / 4\end{array}$ & Bruno avermelhado & 6 & 6.4 \\
\hline $\begin{array}{l}2.5 \mathrm{YR} 6 / 3,2.5 \mathrm{YR} 6 / 4,2.5 \mathrm{YR} \\
7 / 3,2.5 \mathrm{YR} \quad 7 / 4,5 \mathrm{YR} 6 / 3, \\
5 \mathrm{YR} 6 / 4\end{array}$ & Bruno avermelhado claro & 6 & 6.5 \\
\hline $\begin{array}{l}2.5 \mathrm{YR} \quad 2.5 / 3,2.5 \mathrm{YR} \quad 2.5 / 4, \\
2.5 \mathrm{YR} 3 / 3,2.5 \mathrm{YR} 3 / 4,5 \mathrm{YR} \\
2.5 / 2,5 \mathrm{YR} \quad 3 / 2,5 \mathrm{YR} \quad 3 / 3, \\
5 \mathrm{YR} 3 / 4\end{array}$ & Bruno avermelhado escuro & 6 & 6.6 \\
\hline $2.5 \mathrm{Y} 4 / 3,2.5 \mathrm{Y} 4 / 4$ & Bruno oliváceo & 6 & 6.7 \\
\hline $\begin{array}{l}2.5 \mathrm{YR} 5 / 3,2.5 \mathrm{YR} 5 / 4,2.5 \mathrm{YR} \\
5 / 6\end{array}$ & Bruno oliváceo claro & 6 & 6.8 \\
\hline $2.5 \mathrm{Y} 3 / 3$ & Bruno oliváceo escuro & 6 & 6.9 \\
\hline $\begin{array}{l}2.5 \mathrm{Y} 5 / 1,5 \mathrm{Y} 5 / 1,5 \mathrm{Y} 6 / 1, \\
10 \mathrm{YR} 5 / 1,10 \mathrm{YR} 6 / 1,5 \mathrm{YR} \\
5 / 1,5 \mathrm{YR} 6 / 1,7.5 \mathrm{YR} 6 / 1, \\
\text { GLEY 6/, GLEY 5/ }\end{array}$ & Cinzento & 7 & 7.0 \\
\hline $\begin{array}{l}2.5 \mathrm{Y} 7 / 1,2.5 \mathrm{Y} 7 / 2,5 \mathrm{Y} 7 / 1, \\
5 \mathrm{Y} 7 / 2, \mathrm{GLEY} 17 /, 10 \mathrm{R} 7 / 1, \\
5 \mathrm{YR} 7 / 1,7.5 \mathrm{YR} \text { 7/1, 10YR } \\
7 / 1,10 \mathrm{YR} 7 / 2\end{array}$ & Cinzento claro & 7 & 7.1 \\
\hline $\begin{array}{l}5 \mathrm{YR} 6 / 2,5 \mathrm{YR} 7 / 2,7.5 \mathrm{YR} \\
6 / 2,7.5 \mathrm{YR} 7 / 2,7.5 \mathrm{R} 7 / 1\end{array}$ & Cinzento rosado & 7 & 7.2 \\
\hline
\end{tabular}




\begin{tabular}{|c|c|c|c|}
\hline $5 \mathrm{Y} 6 / 2$ & Cinzento olivácea claro & 7 & 7.3 \\
\hline $5 \mathrm{Y} 4 / 2,5 \mathrm{Y} 5 / 2$ & Cinzento oliváceo & 77 & 7.4 \\
\hline $7.5 \mathrm{R} \mathrm{3/1}$ & Cinzento oliváceo escuro & 7 & 7.5 \\
\hline $\begin{array}{l}\text { GLAY1 7/1, GLAY1 8/1, } \\
\text { GLEY2 7/1, GLEY2 8/1 }\end{array}$ & Cinzento esverdeado claro & 7 & 7.6 \\
\hline GLEY1 5/1, GLEY1 6/1 & Cinzento esverdeado & 7 & 7.7 \\
\hline $\begin{array}{l}\text { GLAY1 4/1, GLEY2 4/1, 5Y } \\
3 / 2\end{array}$ & Cinzento esverdeado escuro & 7 & 7.8 \\
\hline GLEY2 3/1 & Cinzento esverdeada muito escuro & 7 & 7.9 \\
\hline $\begin{array}{l}2.5 \mathrm{YR} 5 / 1,2.5 \mathrm{YR} 6 / 1,5 \mathrm{YR} \\
5 / 2,7.5 \mathrm{R} 5 / 1,7.5 \mathrm{R} 6 / 1,10 \mathrm{R} \\
5 / 1,10 \mathrm{R} 6 / 1\end{array}$ & Cinzento avermelhado & 8 & 8.0 \\
\hline $2.5 \mathrm{YR} 7 / 1$ & Cinzento avermelhado claro & 8 & 8.1 \\
\hline $\begin{array}{l}2.5 \mathrm{YR} 3 / 1,2.5 \mathrm{YR} 4 / 1,10 \mathrm{R} \\
3 / 1,10 \mathrm{R} 4 / 1\end{array}$ & Cinzento avermelhado escuro & 8 & 8.2 \\
\hline GLEY2 5/1, GLEY2 6/1 & Cinzento azulado & 8 & 8.3 \\
\hline GLAY2 7/1, GLAY2 8/1 & Cinzento azulada clara & 8 & 8.4 \\
\hline GLEY2 4/1 & Cinzento azulada escuro & 8 & 8.5 \\
\hline 10YR 6/2 & Cinzento brumada claro & 8 & 8.6 \\
\hline $2.5 \mathrm{Y} 6 / 2$ & Cinzento brunado acinzentada & 8 & 8.7 \\
\hline $\begin{array}{l}\text { GLEY1 4, 7.5YR 4/1, 5YR } \\
4 / 1,5 Y 4 / 1\end{array}$ & Cinzento escuro & 8 & 8.8 \\
\hline $\begin{array}{l}\text { GLEY1 3, 5YR 3/1, 2.5Y 3/1, } \\
\text { 7.5YR 3/1 }\end{array}$ & Cinzento muito escuro & 8 & 8.9 \\
\hline $\begin{array}{l}5 \mathrm{Y} 4 / 3,5 \mathrm{Y} 4 / 4,5 \mathrm{Y} 5 / 3,5 \mathrm{Y} \\
5 / 4,5 \mathrm{Y} 5 / 6\end{array}$ & Oliva & 9 & 9.0 \\
\hline $5 Y$ 6/3, 5 Y 6/43 & Oliva claro acinzentado & 9 & 9.1 \\
\hline $\begin{array}{l}\text { GLEY1 6/2, GLEY1 7/2, } \\
\text { GLEY1 8/2 }\end{array}$ & Verde claro acinzentado & 9 & 9.2 \\
\hline $\begin{array}{l}\text { GLEY1 4/2, GLEY1 5/2, } \\
\text { GLEY2 5/1, GLEY2 6/1 }\end{array}$ & Verde acinzentado & 9 & 9.3 \\
\hline $\begin{array}{l}2.5 \mathrm{YR} 2.5 / 1,7.5 \mathrm{R} 2.5 / 1,10 \mathrm{R} \\
2.5 / 1\end{array}$ & Preto avermelhado & 10 & 10.0 \\
\hline GLEY2 2.5/1 & Preto azulado & 10 & 10.1 \\
\hline GLEY2 2.5/1, GLEY1 2.5/1 & Preto esverdeado & 10 & 10.2 \\
\hline 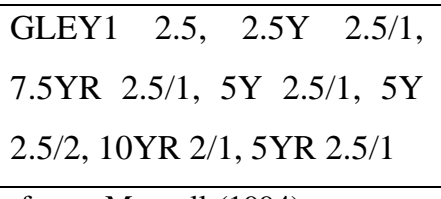 & Preto & 10 & 10.3 \\
\hline
\end{tabular}

${ }^{1}$ Cor conforme Munsell (1994) expressa em três parâmetros matiz, valor e croma. ${ }^{2}$ Tradução da cor conforme Santos et al. (2005).

${ }^{3}$ Valores de classificação para análises discretas. ${ }^{4}$ Valores de classificação para análises contínuas. Fonte: Autores (2021). 


\section{Caracterização das plantas}

A pesquisa foi conduzida no campo experimental ( $3^{\circ} 41^{\prime} 09,78^{\prime \prime S}$ e $39^{\circ} 20^{\prime} 28,01^{\prime \prime W}$, a $78 \mathrm{~m}$ acima do nível do mar) da mesma instituição. O clima da região, segundo Alvares et al. (2014) é BSh (clima semiárido), caracterizado pela baixa umidade e chuvas irregulares. A área trabalhada apresenta um Latossolo amarelo distrófico, textura franca arenosa a franco argilosa, relevo suave ondulado (Santos et al., 2013).

Dois meses antes da semeadura foram realizadas uma aração e uma gradagem visando a descompactação, nivelamento e correção do solo. Na semana que antecedeu a semeadura foram realizadas mais duas gradagens.

No ensaio utilizou-se o delineamento experimental de blocos ao acaso, com quatro repetições por genótipo. As parcelas foram compostas por três linhas espaçadas em 1,0 metro, com espaçamento entre plantas de 0,5 metro e espaçamento de 1,5 metros entre variedades na linha e entre blocos, totalizando $8,75 \mathrm{~m}^{2}$, sendo a área útil a planta central. As covas receberam conjuntamente três sementes de fava e três sementes de milho (variedade) que serviu como tutor para leguminosa. Trinta dias após emergência, as plantas foram desbastadas e, de cada espécie, ficou apenas uma planta por cova. Realizou-se ao longo do ciclo da cultura, capinas manuais, irrigações suplementares (por gotejamento) e adubação conforme necessidade da cultura e análise do solo.

Durante a condução do experimento foram avaliadas características nas fases vegetativas e reprodutivas. Utilizou-se como documento de referência, as informações produzidas pelos descritores de P. lunatus (IPGRI, 2001). Na fase vegetativa foram anotados: cor dos cotilédones, cor do hipocótilo, comprimento do folíolo central, largura do folíolo central, forma do folíolo, hábito de crescimento. Na fase reprodutiva foram observadas as seguintes características, tempo até a floração, comprimento do botão floral, cor das asas, cor do estandarte, cor da quilha, comprimento da vagem, curvatura da vagem, forma do ápice da vagem e foram adicionados quantidade de vagem/planta, largura da vagem, espessura da vagem, deiscência das vagens, número de sementes/vagem, quantidade de sementes/planta e produção de sementes/planta.

\section{Análise dos dados}

Após a obtenção de todos os dados (qualitativos e quantitativos) aplicou-se estatística descritiva. Nos dados de natureza qualitativa empregou-se frequência (porcentagem), e para os dados de natureza quantitativa, frequência, média, desvio padrão, formação de classes, construção de histogramas, polígonos de frequência e a representação gráfica do resumo de cinco pontos (boxplots). As análises estatísticas foram realizadas com auxílio do programa SigmaPlot ${ }^{\circledR}$.

\section{Resultados}

Ao realizar a análise da semente verificou-se que a distribuição das classes para comprimento teve comportamento unimodal e distribuição assimétrica à direita (Figura 1A). O comprimento da semente variou entre 10,98 a 19,36 mm, sendo que $55,71 \%$ da frequência estava compreendida entre três classes de comprimento, sendo elas 13,07 mm (24,29\%), $14,12 \mathrm{~mm}$ $(15,71 \%)$ e $15,17 \mathrm{~mm}(15,71 \%)$. No boxplot o $1^{\circ}$ quartil $\left(\mathrm{Q}_{1}\right)$ representa $25 \%$ das amostras com comprimento de até $12,90 \mathrm{~mm}$, o $2^{\circ}$ quartil $\left(\mathrm{Q}_{2}\right)$ representa $50 \%$ das amostras de comprimento até $13,85 \mathrm{~mm}$ e no $3^{\circ}$ quartil $\left(\mathrm{Q}_{3}\right)$ estão $75 \%$ das amostras com comprimento de até 15,68 mm (Figura 1B). O comprimento das sementes possui média 14,22 mm, mediana de 13,85 mm, desvio padrão de 1,99 mm e coeficiente de variação de 14,00\%.

$\mathrm{Na}$ largura das sementes houve uma distribuição unimodal com maior frequência $(32,86 \%)$ observada em sementes com $9,76 \mathrm{~mm}$ de largura (Figura 2A). A curva para esta característica, apresentou distribuição assimétrica positiva, com variações entre 8,03 e 12,64 mm. Os valores para quartis foram, 9,64 mm $\left(\mathrm{Q}_{1}\right), 10,10 \mathrm{~mm}\left(\mathrm{Q}_{2}\right)$ e 10,92 mm ( $\left.\mathrm{Q}_{3}\right)$ (Figura 2B). Enquanto que para a média foram $10,21 \mathrm{~mm}$, desvio padrão de $0,99 \mathrm{~mm}$ e coeficiente de variação $9,69 \%$. 
Figura 1 - Histograma, polígono de frequência (A) e boxplot (B) do comprimento da semente de 70 variedades de Phaseolus lunatus. Umirim-CE, 2017.

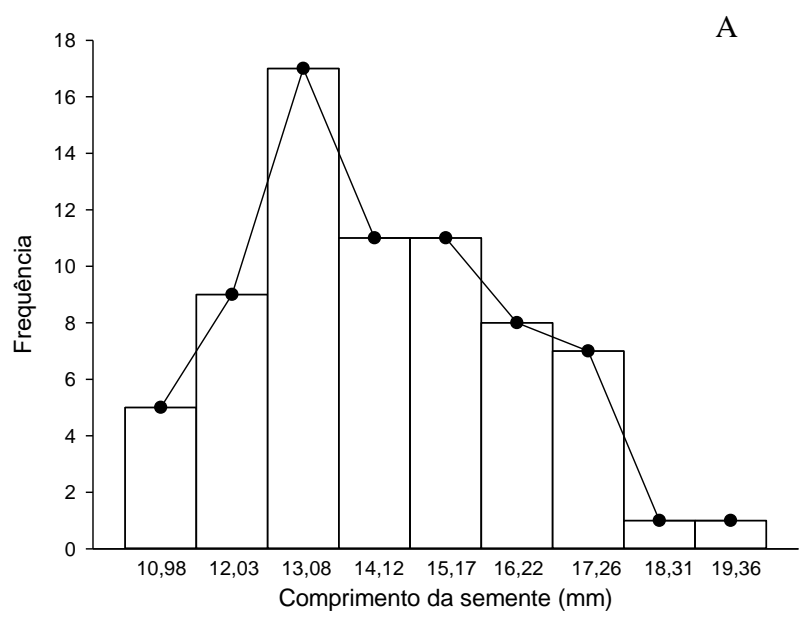

B

Fonte: Autores (2021).

Figura 2 - Histograma, polígono de frequência (A) e boxplot (B) da largura da semente de 70 variedades de Phaseolus lunatus. Umirim-CE, 2017.
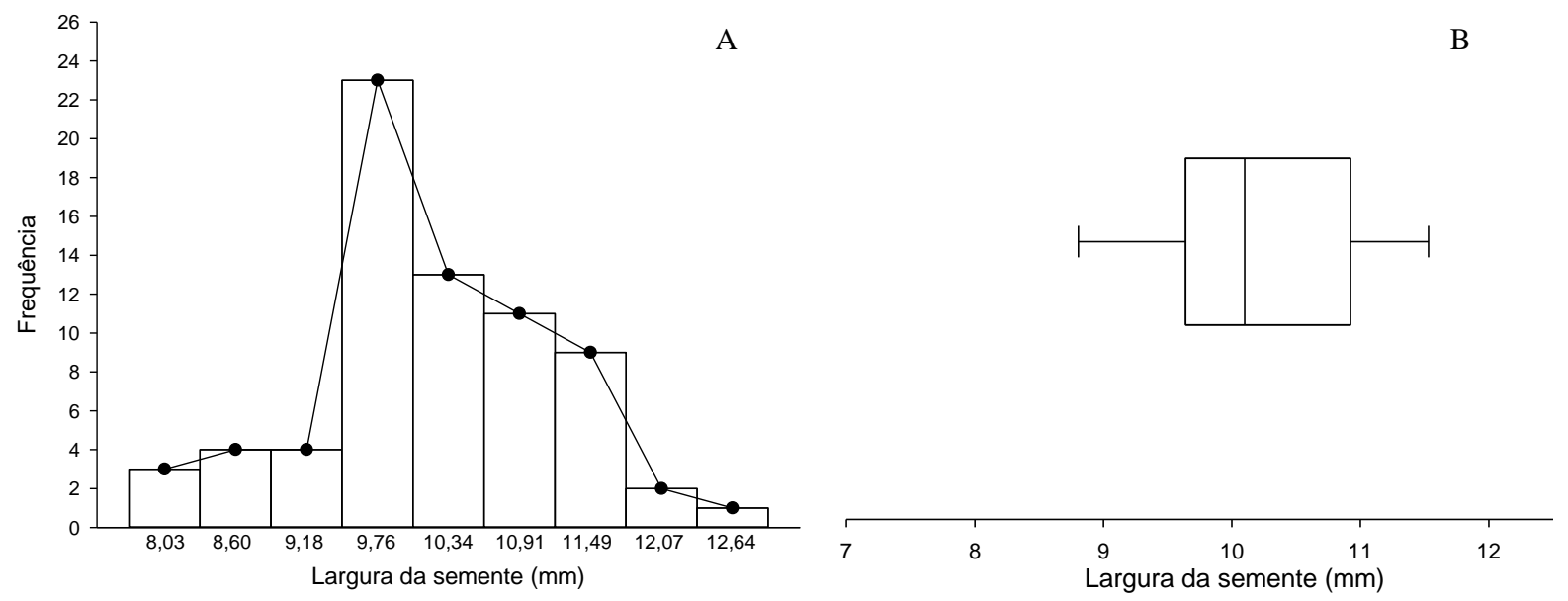

Fonte: Autores (2021)

Para espessura das sementes ocorreu uma distribuição multimodal, com maiores frequências em 5,74 mm (30\%) e 6,02 mm (28,57\%) (Figura 3A). O intervalo de variação ficou compreendido entre 4,89 e 7,16 mm, enquanto os três quartis seguiram a respectiva ordem, $\mathrm{Q}_{1^{-}} 5,70 \mathrm{~mm}, \mathrm{Q}_{2^{-}} 5,90 \mathrm{~mm}$ e $\mathrm{Q}_{3^{-}}$6,26 $\mathrm{mm}$ (Figura 3B). Tendo-se para média 5,95 mm, desvio padrão 0,48 mm e coeficiente de variação $8,07 \%$. 
Figura 3 - Histograma, polígono de frequência (A) e boxplot (B) da espessura da semente de 70 variedades de Phaseolus lunatus. Umirim-CE, 2017.

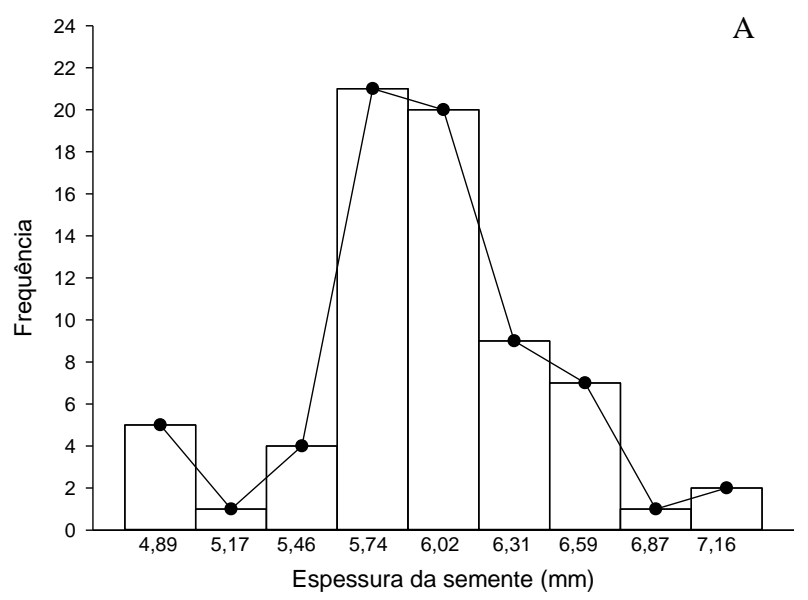

A $\quad$ B

Fonte: Autores (2020).

As variedades de fava apresentaram sementes na forma elíptica $(35,71 \%)$ e esférica $(64,29 \%)$ (Figura 4A). Para o perfil das sementes foram encontradas as de formas achatadas $(97,14 \%)$ e as semicheias $(2,86 \%)$ (Figura 4B).

No peso de 1000 sementes a distribuição foi unimodal com maior frequência $(25,71 \%)$ observada em sementes com 533,10 gramas (Figura 5A). A curva para esta característica apresentou distribuição assimétrica à esquerda com valores mínimo e máximo de 241,54 e 824,66 gramas, respectivamente. Os valores para os quartis foram, 466,30 g $\left(\mathrm{Q}_{1}\right), 551,15 \mathrm{~g}\left(\mathrm{Q}_{2}\right), 635,65$ $\mathrm{g}\left(\mathrm{Q}_{3}\right)$ (Figura 5B) e para média, desvio padrão e coeficiente de variação foram, respectivamente, 548,89 g, 138,62 g, 25,25\%.

Figura 4 - Frequências da forma (A) e perfil (B) das sementes de 70 variedades de Phaseolus lunatus. Umirim-CE, 2017.
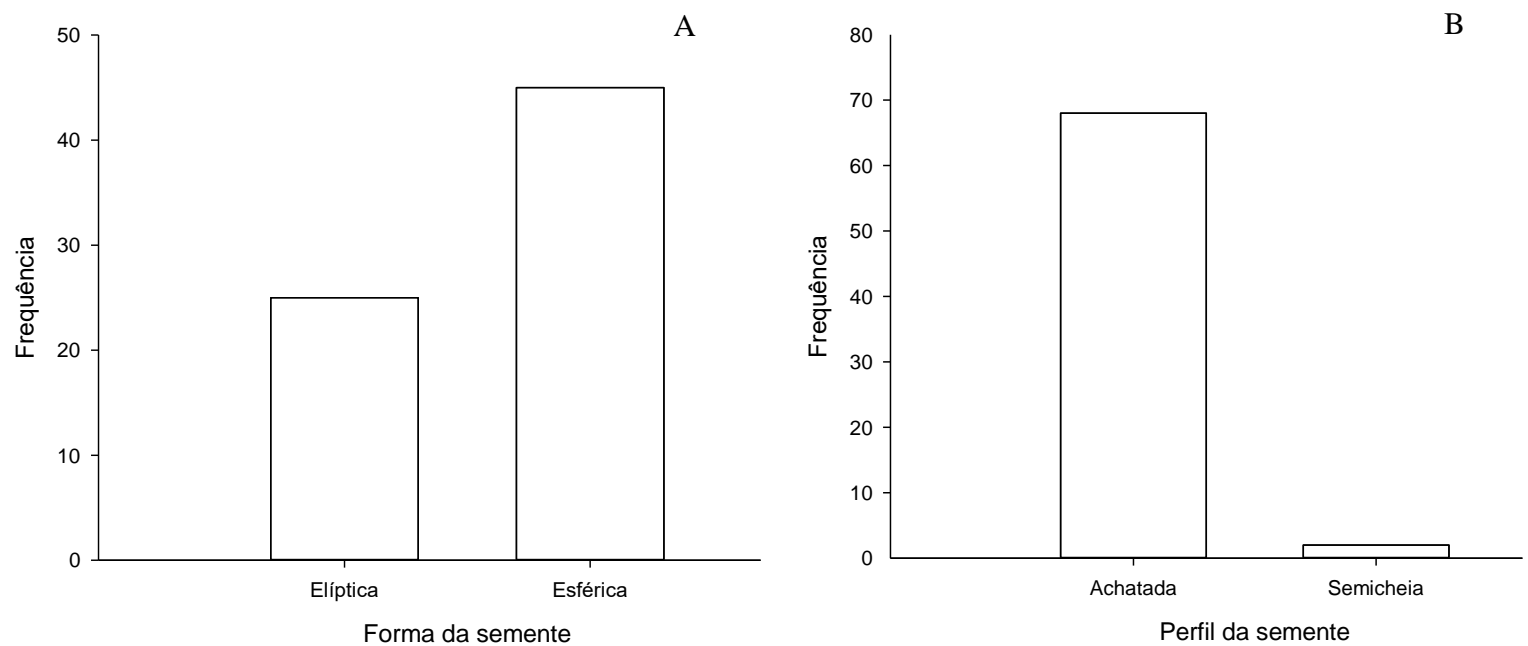

Fonte: Autores (2020). 
Figura 5 - Histograma, polígono de frequência (A) e boxplot (B) do peso de 100 de sementes de 70 variedades de Phaseolus lunatus. Umirim-CE, 2017.

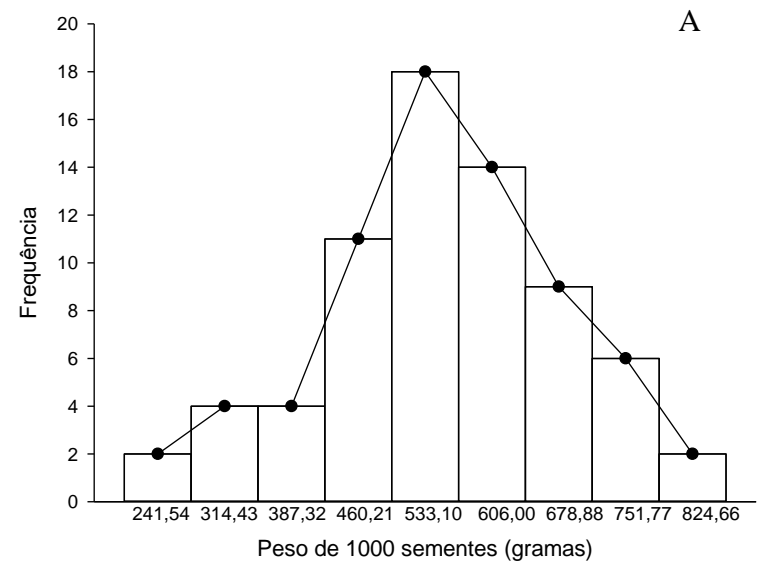

B

Fonte: Autores (2020).

As sementes de fava apresentaram uma diversidade de cores (Figura 6A), sendo que na cor principal do tegumento predominou as colorações, branca $(34,29 \%)$ e amarelo claro-acinzentado $(28,57 \%)$. Quatorze variedades apresentaram cor secundária, sendo 7 pretas-avermelhadas, 5 vermelhas-escuras, 1 amarela-brunado, 1 bruno avermelhado escuro e 1 vermelhaamarelada (Figura 6B).

Figura 6 - Frequência da cor principal e secundária do tegumento de sementes de 70 variedades de Phaseolus lunatus. UmirimCE, 2017.
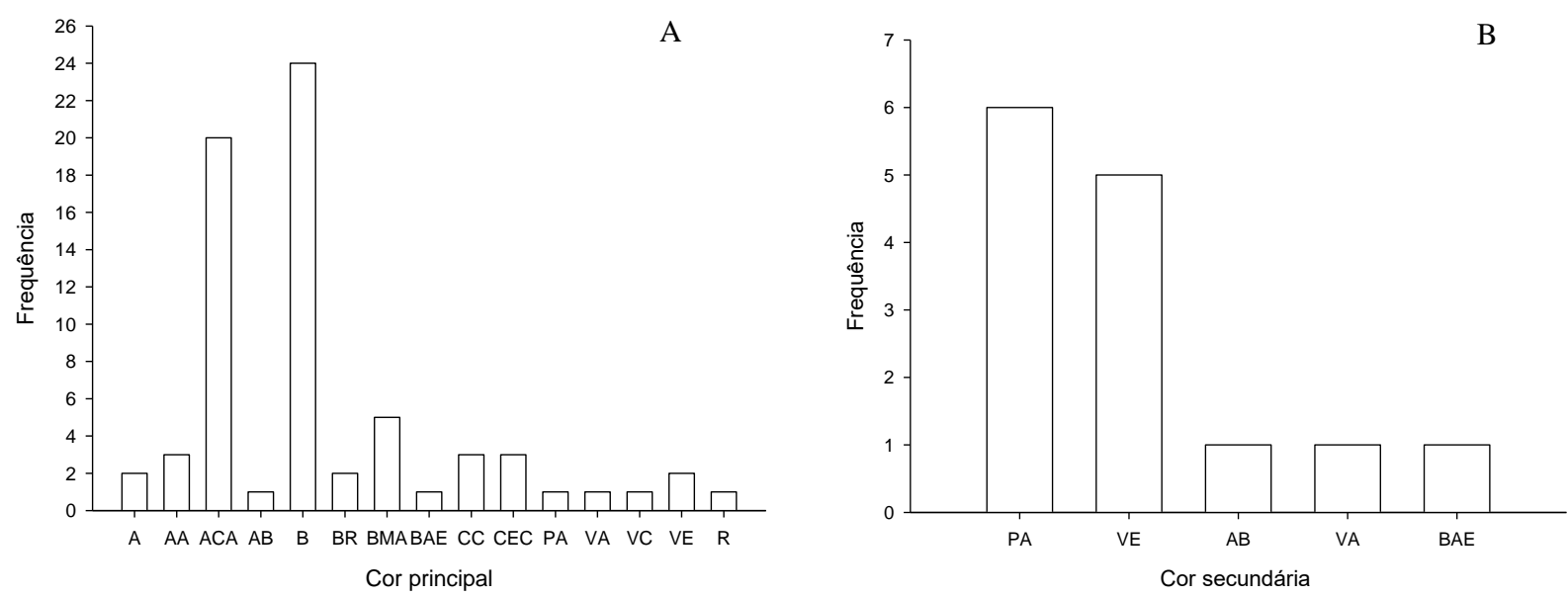

A - amarela, AA - amarelo avermelhado, AB - amarelo brunado, ACA - amarelo claro-acinzentado, B - branca, BAE - bruno avermelhado escuro, BMA - bruno muito claro, BR - branca rosada, CC - cinzento esverdeado claro, PA - preto avermelhado, VA - vermelho amarelado, VC - vermelho claro, VE - vermelho escuro e R - rosado. Fonte: Autores (2021).

Dentre as características observadas para planta, verificou-se que as plântulas das favas emergiram entre 5 e 10 dias e apresentaram cotilédones na coloração verde $(69,64 \%)$ ou púrpura $(30,36 \%)$ (Figura 7A). Para cor do hipocótilo ocorreram as colorações verde $(67,14 \%)$, vermelho-púrpura (1,79\%) e púrpura (31,07\%) (Figura 7B), tendo ficado ausentes os hipocótilos na cor vermelha e cotilédones na cor branca. 
Figura 7 - Frequências da cor dos cotilédones (A) e cor do hipocótilo (B) em 70 variedades de Phaseolus lunatus. Umirim-CE, 2017.
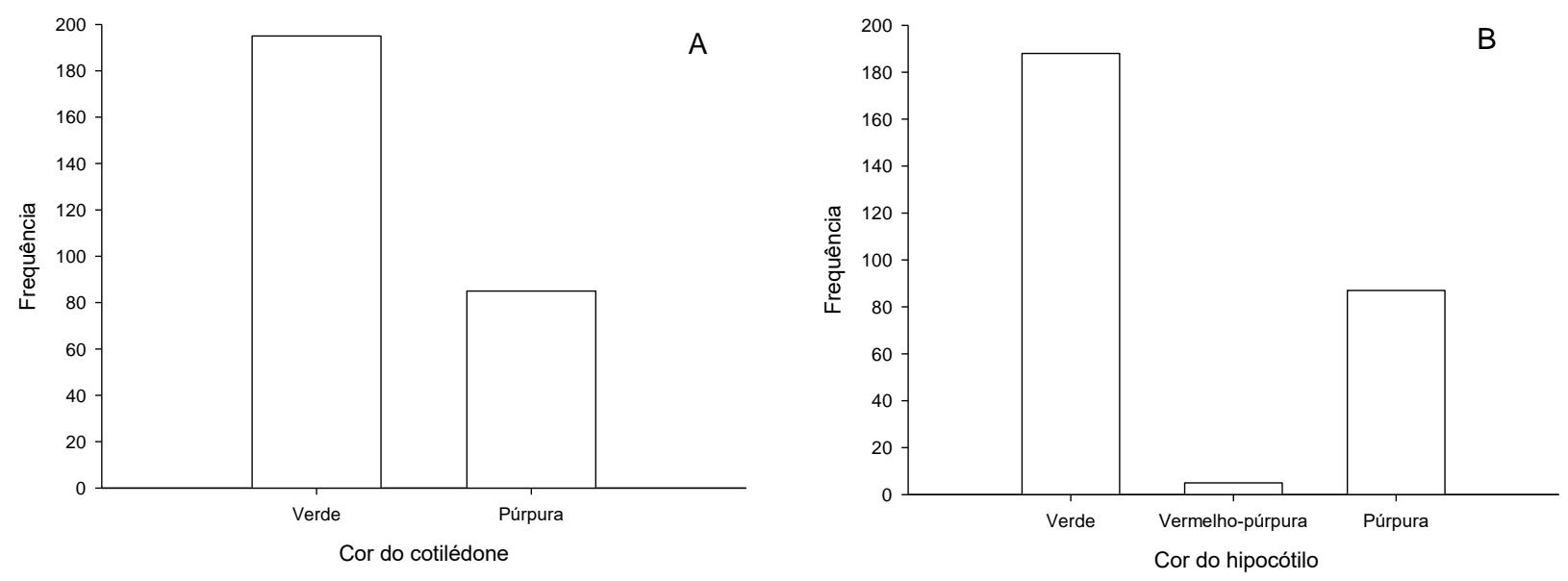

Fonte: Autores (2020).

O comprimento do folíolo central variou entre 2,53 a 11,07 cm, já a apresentação gráfica do histograma e polígono de frequência apresentou distribuição bimodal, sendo a maior frequência (19,29\%) observada nas folhas com $5,73 \mathrm{~cm}$ de comprimento (Figura $8 \mathrm{~A})$. No boxplot, o $1^{\circ}$ quartil $\left(\mathrm{Q}_{1}\right)$ representou $25 \%$ amostras com comprimento de até $4,5 \mathrm{~cm}$, o $2^{\circ}$ quartil $\left(\mathrm{Q}_{2}\right)$, representou $50 \%$ amostras de comprimento de até $6,00 \mathrm{~cm}$ e o $3^{\circ}$ quartil $\left(\mathrm{Q}_{3}\right)$ representou $75 \%$ amostras com comprimento de até 8,30 cm (Figura 8B). O comprimento do folíolo possuía média de 6,33 cm, mediana de 6,00 cm, desvio padrão de 2,36 cm e coeficiente de variação de $37,28 \%$.

Figura 8 - Histograma, polígono de frequência (A) e boxplot (B) do comprimento do folíolo central de 70 variedades de Phaseolus lunatus. Umirim-CE, 2017.

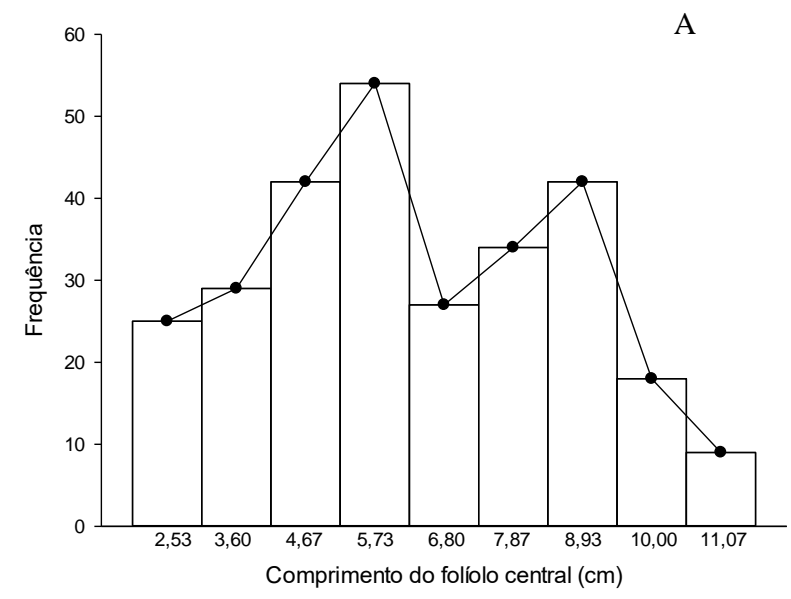

B

Fonte: Autores (2020).

Para largura do folíolo central houve variação entre 2,01 a 10,09 cm. A distribuição foi unimodal, com distribuição assimétrica à direita, sendo a maior frequência (23,93\%) em folíolos com 4,03 cm de largura (Figura 9A). Enquanto, os três quartis ficaram na seguinte ordem: $Q_{1}-3,00 \mathrm{~cm}, Q_{2}-4,10 \mathrm{~cm}$ e $Q_{3}-5,40 \mathrm{~cm}$ (Figura 9B). Foram observados ainda valores de 4,35 
cm para média, 4,10 cm para mediana, 1,63 cm para desvio padrão e 37,47\% para coeficiente de variação. Da relação entre comprimento e largura do folíolo obtém-se a forma do folíolo da planta. Foram encontradas três formas do folíolo, redonda $(36,07 \%)$, oval $(34,64 \%)$ e oval-lanceolada $(29,29 \%)$, tendo ficado ausentes os folíolos lanceolados e linear-lanceolados (Figura $10)$.

Figura 9 - Histograma, polígono de frequência (A) e boxplot (B) da largura do folíolo central de 70 variedades de Phaseolus lunatus. Umirim-CE, 2017.
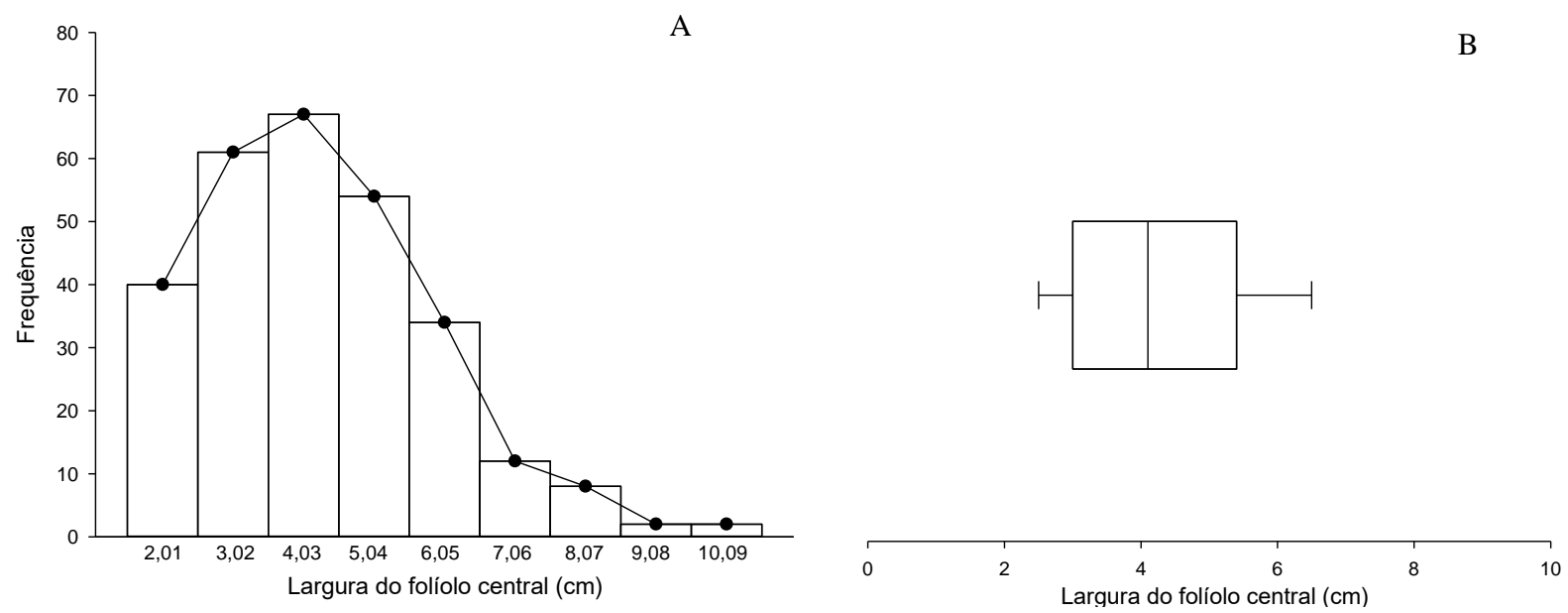

Fonte: Autores (2020).

Figura 10 - Frequência da forma do folíolo central de 70 variedades de Phaseolus lunatus. Umirim-CE, 2017.

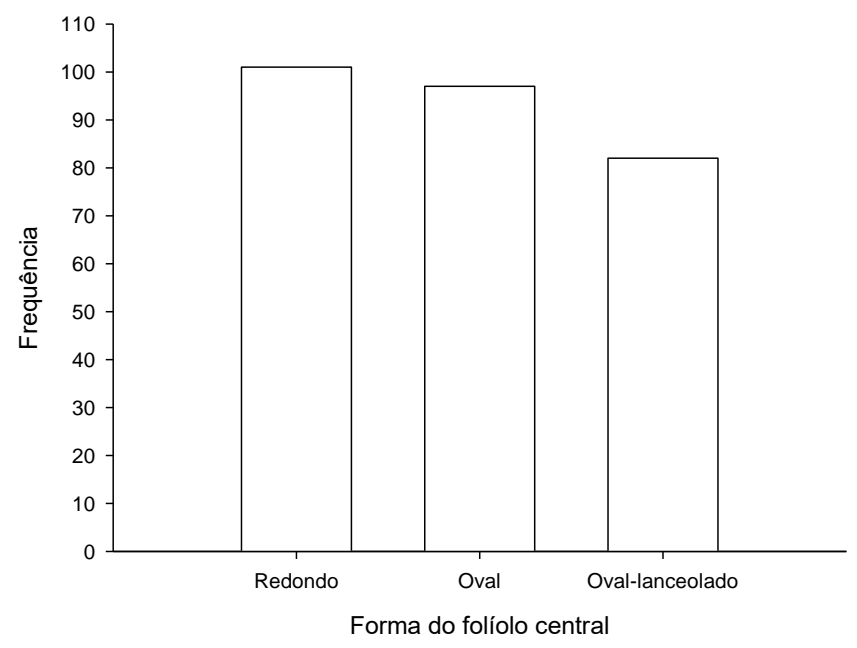

Fonte: Autores (2020).

No tamanho do botão floral houve uma oscilação entre 4,56 e 7,84 mm, a distribuição foi unimodal com assimetria negativa (Figura 11A), a média foi de $6,32 \mathrm{~mm}$, a mediana de $6,41 \mathrm{~mm}$, o desvio padrão de 0,76 mm e o coeficiente de variação de $12,02 \%$. Os valores observados na amostra (Figura 11B) situaram-se abaixo de 5,76 $\left(\mathrm{Q}_{1}\right), 6,41\left(\mathrm{Q}_{2}\right)$ e 6,92 mm $\left(\mathrm{Q}_{3}\right)$. Quanto à flor da fava, está se divide em três partes: asas, quilha e estandarte. As variedades de favas pesquisadas apresentaram asas na 
coloração branca (60\%), verde-amarelada (21,07\%) e violeta (19,93\%) (Figura 12A), já a quilha apresentou coloração esverdeada $(83,21 \%)$ e tingida $(16,79 \%)$ (Figura 13B), enquanto o estandarte apresentou coloração verde-amarelado (80,36\%), violeta $(18,21 \%)$ e rosa-claro $(1,43 \%)$ (Figura $12 \mathrm{C})$.

Figura 11 - Histograma, polígono de frequência e boxplot do tamanho do botão floral de 70 variedades de Phaseolus lunatus, Umirim-CE, 2017.

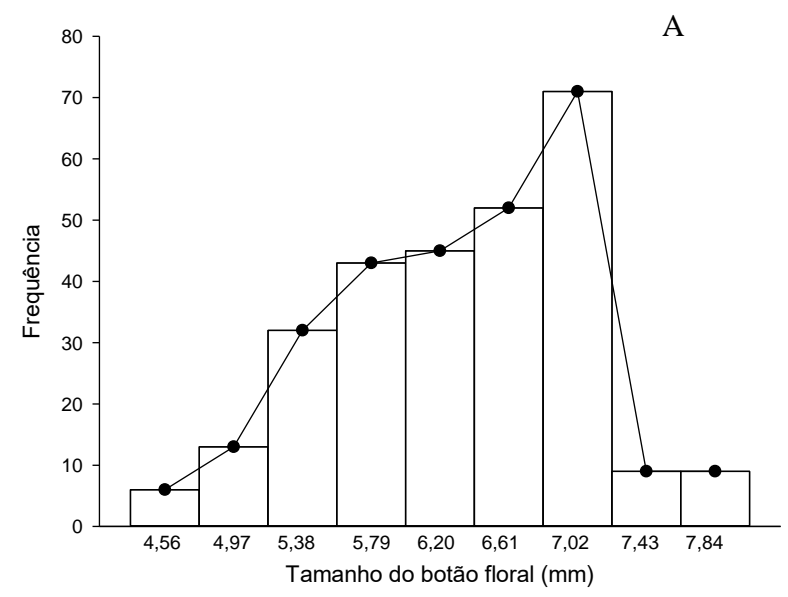

Figura 12 - Frequência da cor das partes da flor, asa (A), quilha (B) e estandarte (C) de 70 variedades de Phaseolus lunatus, Umirim-CE, 2017.
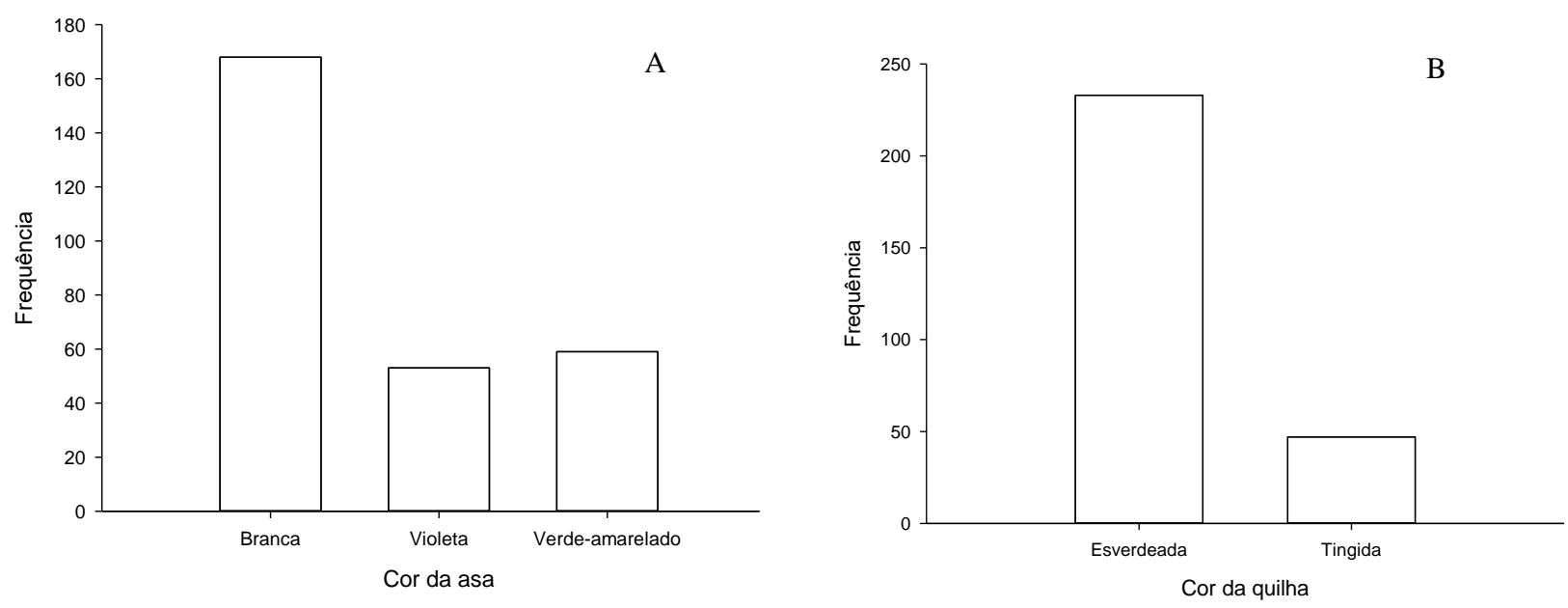


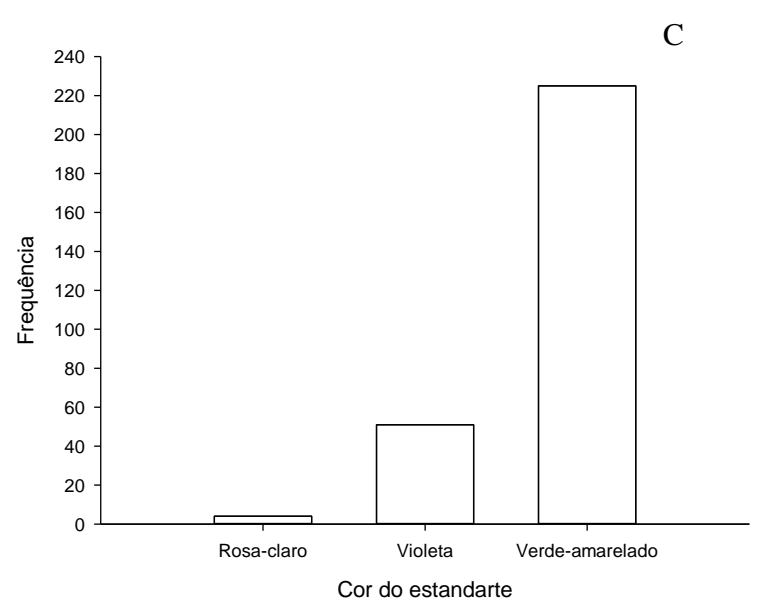

Fonte: Autores (2020).

Observou-se para tempo da emergência até floração uma distribuição unimodal, com assimétrica à esquerda (Figura 13A) e variações entre 50,11 a 115,89 dias, com maior frequência aos 91,22 dias (28,93\%). Em $\mathrm{Q}_{1}$, estavam as amostras com até 75 dias, em $\mathrm{Q}_{2}$, as de até 85 dias e em $\mathrm{Q}_{3}$, as de até 90 dias (Figura 13B). Os valores da média, mediana e desvio padrão foram, respectivamente: 82,50 dias; 85,00 dias; 15,37 dias e do coeficiente de variação foi de $18,63 \%$.

Figura 13 - Histograma, polígono de frequência (A) e boxplot (B) do tempo até a floração de 70 variedades de Phaseolus lunatus. Umirim-CE, 2017.
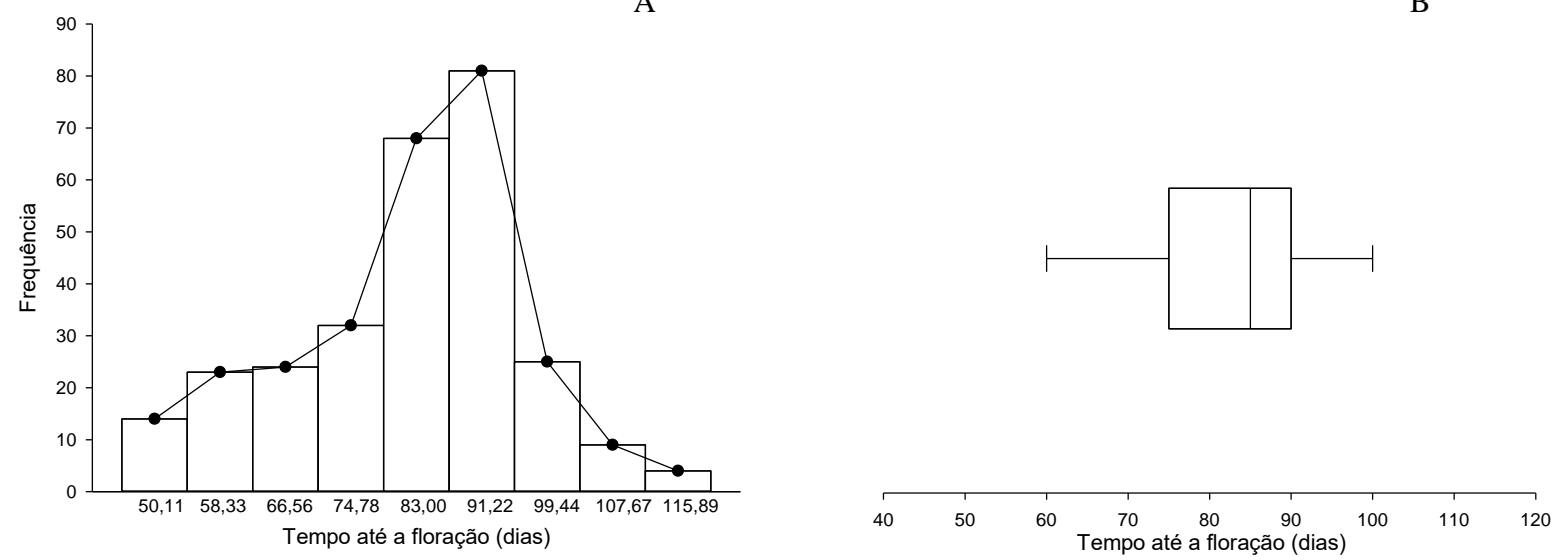

Fonte: Autores (2020).

Na quantidade de vagem/planta, a distribuição foi multimodal (Figura 14A). A representação gráfica do resumo de cinco pontos foi de 11,39 unidades (menor valor), 15 unidades $\left(\mathrm{Q}_{1}\right), 18$ unidades $\left(\mathrm{Q}_{2}\right), 22$ unidades $\left(\mathrm{Q}_{3}\right)$ e 33,62 unidades (maior valor), ou seja, 50\% dos valores observados na amostra situaram-se abaixo da mediana (15 unidade) (Figura 14B), sendo a maior frequência em 14,17 unidades, que representa 28,93\% do total das amostras. Esta característica portou média de 18,97 unidades, desvio padrão de 5,78 unidades e coeficiente de variação de 30,47\%. As vagens das variedades apresentaram a forma do ápice, curtos $(48,57 \%)$, médios $(4,29 \%)$, longos $(5,71 \%)$ e grossos $(41,43 \%)$ (Figura 15A) e curvaturas direta $(24,29 \%)$, ligeiramente curva $(47,14 \%)$ e curva $(28,57 \%)$ (Figura $15 B)$. 
Figura 14 - Histograma, polígono de frequência (A) e boxplot (B) quantidade de vagem/planta de 70 variedades de Phaseolus lunatus. Umirim-CE, 2017.

A

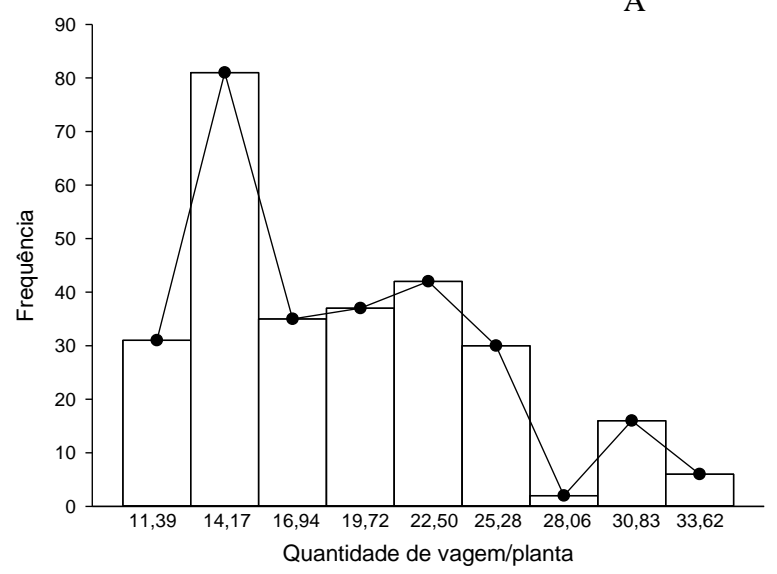

B

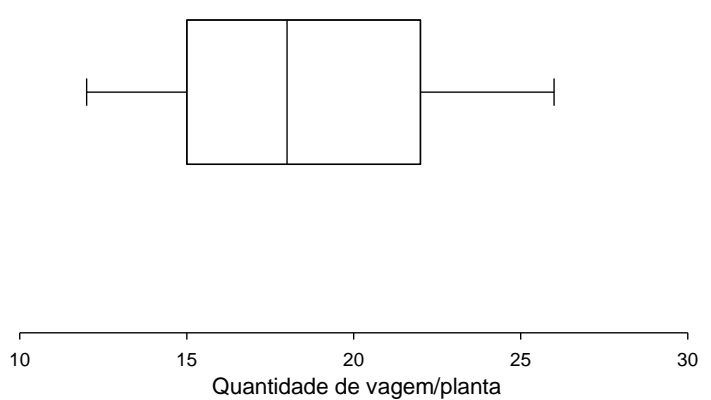

Fonte: Autores (2020).

Figura 15 - Frequência da forma do ápice da vagem (A) e frequência da curva da vagem (B) de 70 variedades de Phaseolus lunatus. Umirim-CE, 2017.
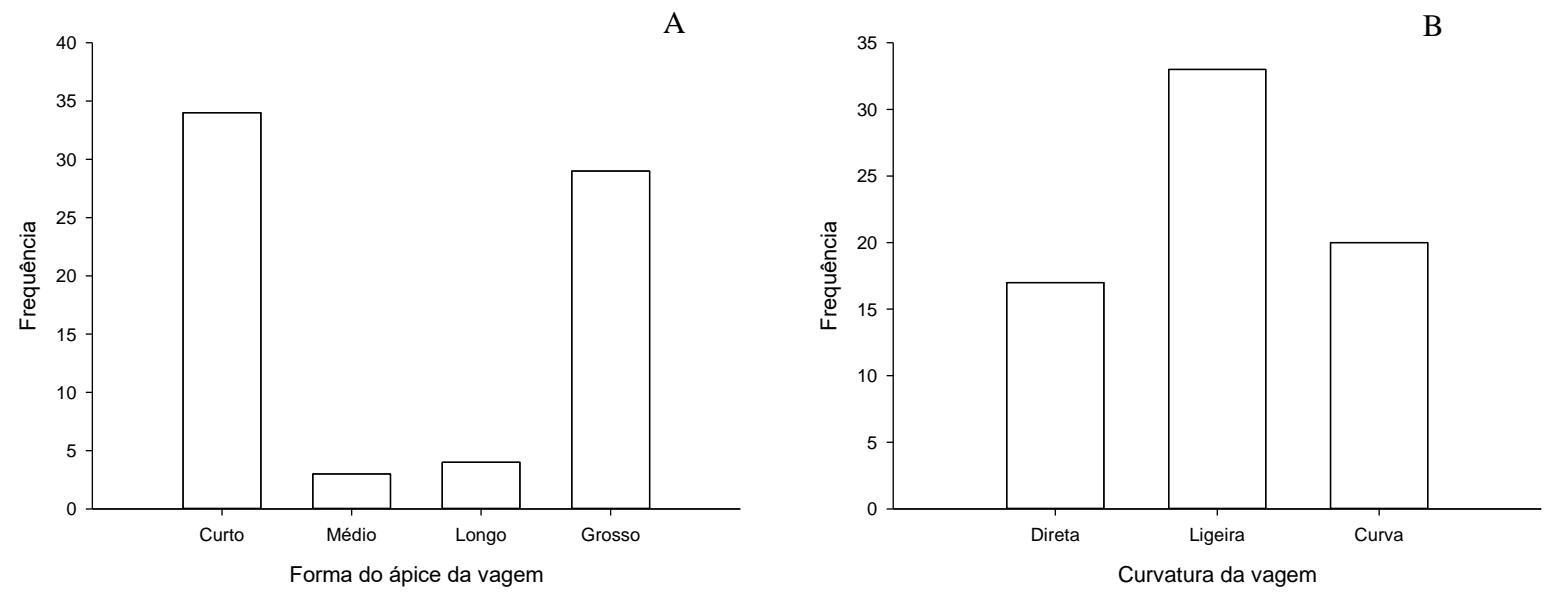

Fonte: Autores (2020).

A distribuição das classes para o comprimento da vagem de fava teve comportamento bimodal, com variação entre 5,42 e $8,54 \mathrm{~cm}$, amplitude de $3,02 \mathrm{~cm}$, média de $6,76 \mathrm{~cm}$, desvio padrão de $0,74 \mathrm{~cm}$ e coeficiente de variação de $10,95 \%$ (Figura 16A). Verificou-se que a maior frequência $(24,29 \%)$ das vagens estava na classe de comprimento de $6,20 \mathrm{~cm}$. Observou-se ainda que 25, 50 e 75\% dos valores da amostra ficaram, respectivamente em 6,22 $\left(\mathrm{Q}_{1}\right), 6,58\left(\mathrm{Q}_{2}\right)$ e 7,31 cm $\left(\mathrm{Q}_{3}\right)$ (Figura 16B). 
Figura 16 - Histograma, polígono de frequência (A) e boxplot (B) do comprimento da vagem de 70 variedades de Phaseolus lunatus, Umirim-CE, 2017.

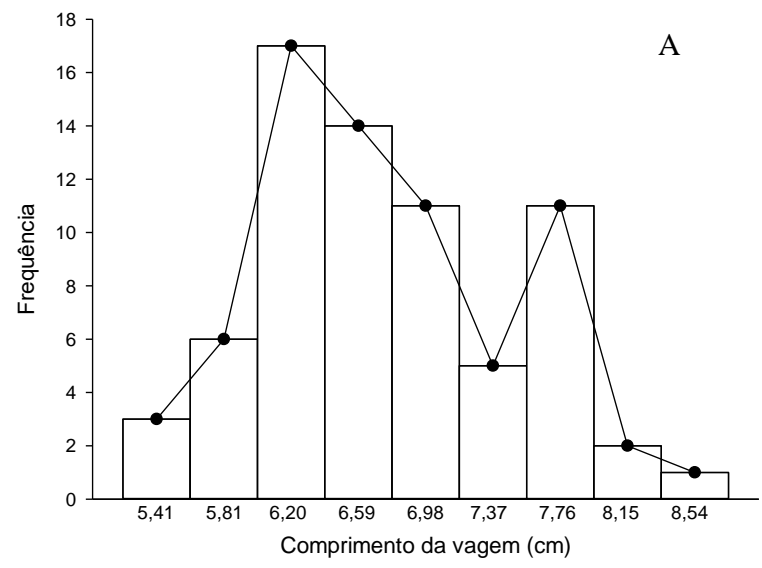

B

Fonte: Autores (2020).

Na largura da vagem, a variação ocorreu de 0,70 a 2,30 cm com média de $1,58 \mathrm{~cm}$, desvio padrão de $0,20 \mathrm{~cm}$ e $12,66 \%$ de coeficiente de variação. A maior frequência está na classe 1,50 cm que representa 47,14\% da amostra (Figura 17A). A distribuição é unimodal com assimetria à direita. No Figura boxplot (Figura 17B) foram observados os seguintes valores: 1,50 $\left(\mathrm{Q}_{1}\right), 1,56\left(\mathrm{Q}_{2}\right)$ e $1,67 \mathrm{~cm}\left(\mathrm{Q}_{3}\right)$.

Para espessura da vagem, as amostras seguiram a distribuição unimodal com assimetria positiva, sendo a maior frequência $(41,43 \%$ ) em 0,65 cm (Figura 18A). Os valores para o resumo dos cinco pontos foi 0,25 cm (menor valor), 0,65 cm $\left(\mathrm{Q}_{1}\right), 0,68 \mathrm{~cm}\left(\mathrm{Q}_{2}\right), 0,75 \mathrm{~cm}\left(\mathrm{Q}_{3}\right)$ e 1,05 cm (maior valor) (Figura 18B). Tratando-se dos valores da média, desvio padrão e coeficiente de variação, os valores encontrados foram respectivamente, $0,69 \mathrm{~cm}, 0,11 \mathrm{~cm} \mathrm{e} 15,94 \%$.

Figura 17 - Histograma, polígono de frequência (A) e boxplot (B) da largura da vagem de 70 variedades de Phaseolus lunatus, Umirim-CE, 2017.
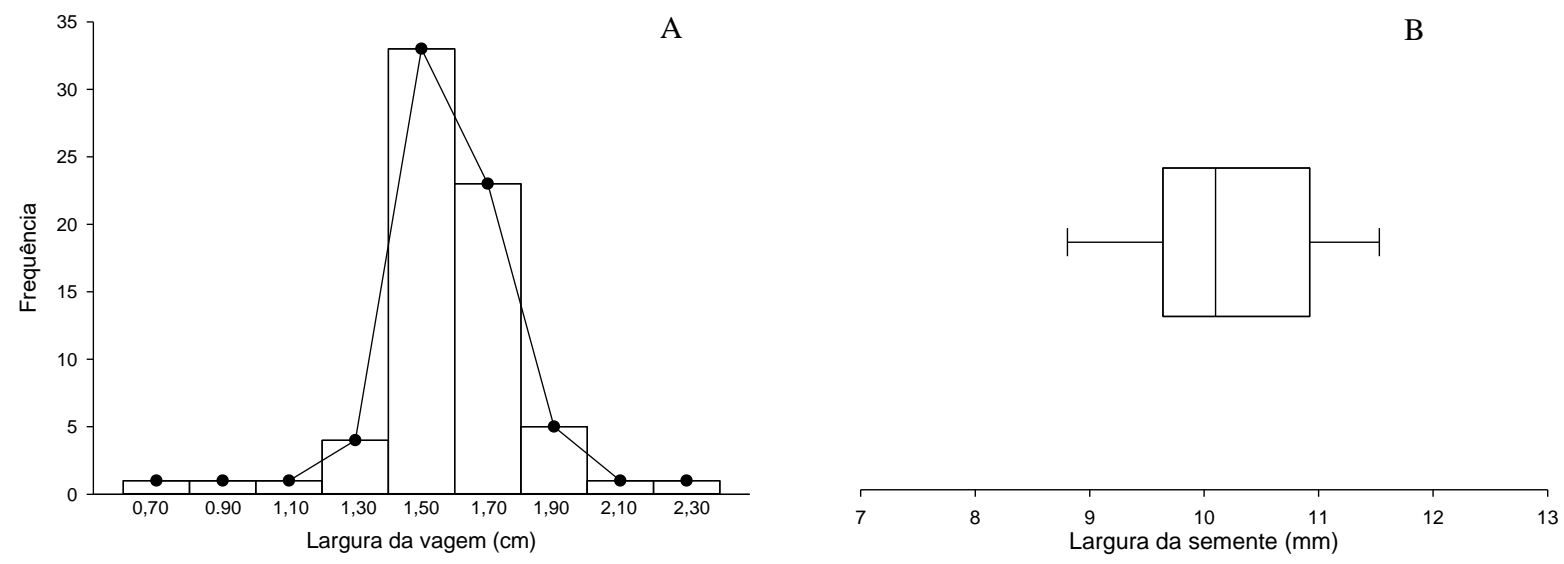

Fonte: Autores (2020). 
Figura 18 - Histograma, polígono de frequência (A) e boxplot (B) da espessura da vagem de 70 variedades de Phaseolus lunatus, Umirim-CE, 2017.

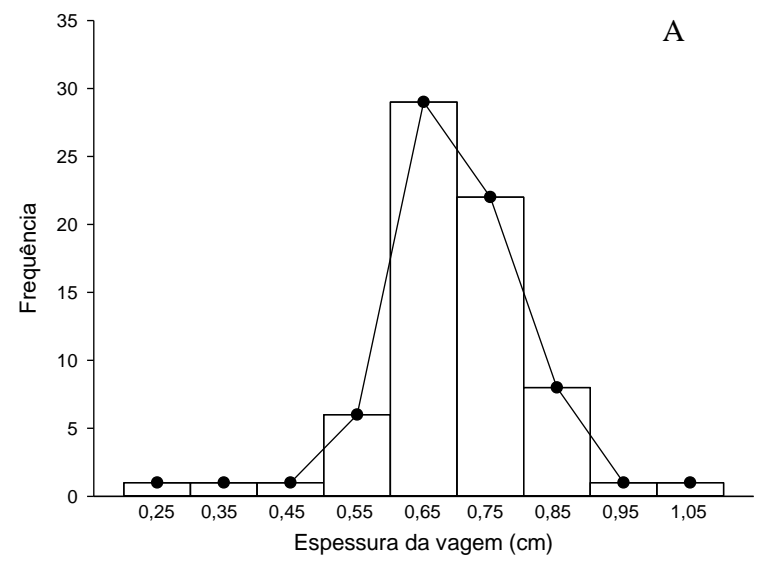

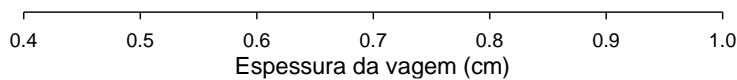

Fonte: Autores (2020).

O número de sementes/vagem apresentou distribuição unimodal com assimetria negativa e maior frequência (30,00\%) na classe 2,88 sementes (Figura 19A). Os valores variaram entre 1,99 a 3,18 sementes/vagem, enquanto os quartis apresentaram Q1- 2,58, Q2- 2,75 e Q3- 2,92 sementes/vagem (Figura 19B) e média 2,76; desvio padrão 0,24; e coeficiente de variação 8,69\%. A quantidade de sementes/planta apresentou oscilação de 23,29 a 86,71 sementes (Figura 20A), com maior frequência (25\%) em 33,85. Os valores para quartis, foram $\mathrm{Q}_{1^{-}}$36, $\mathrm{Q}_{2^{-}} 49$ e $\mathrm{Q}_{3}-62$ sementes/planta (Figura 20B) e para média de 49,97; mediana de 49,00; desvio padrão de 17,53; e coeficiente de variação de 35,08\%.

Figura 19 - Histograma, polígono de frequência (A) e boxplot (B) do número de sementes/vagem de 70 variedades de Phaseolus lunatus, Umirim-CE, 2017.
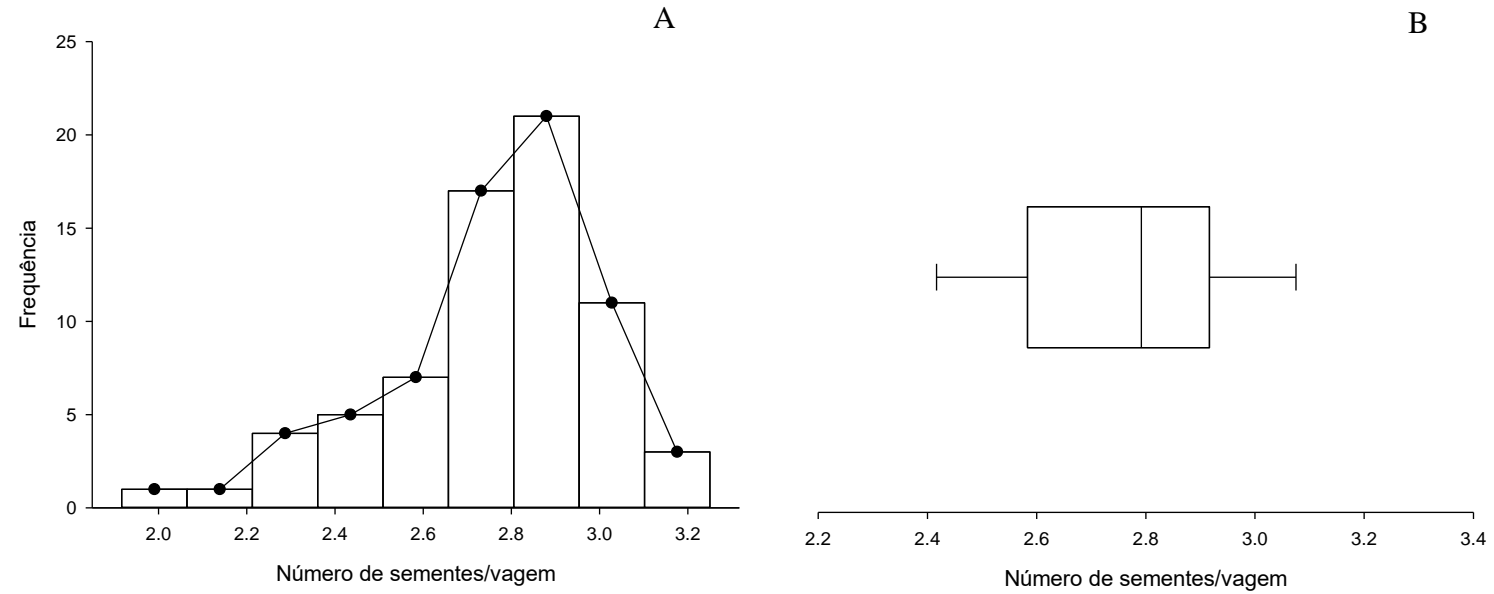

Fonte: Autores (2020). 
Figura 20 - Histograma, polígono de frequência (A) e boxplot (B) da quantidade de sementes/planta de 70 variedades de Phaseolus lunatus, Umirim-CE, 2017.
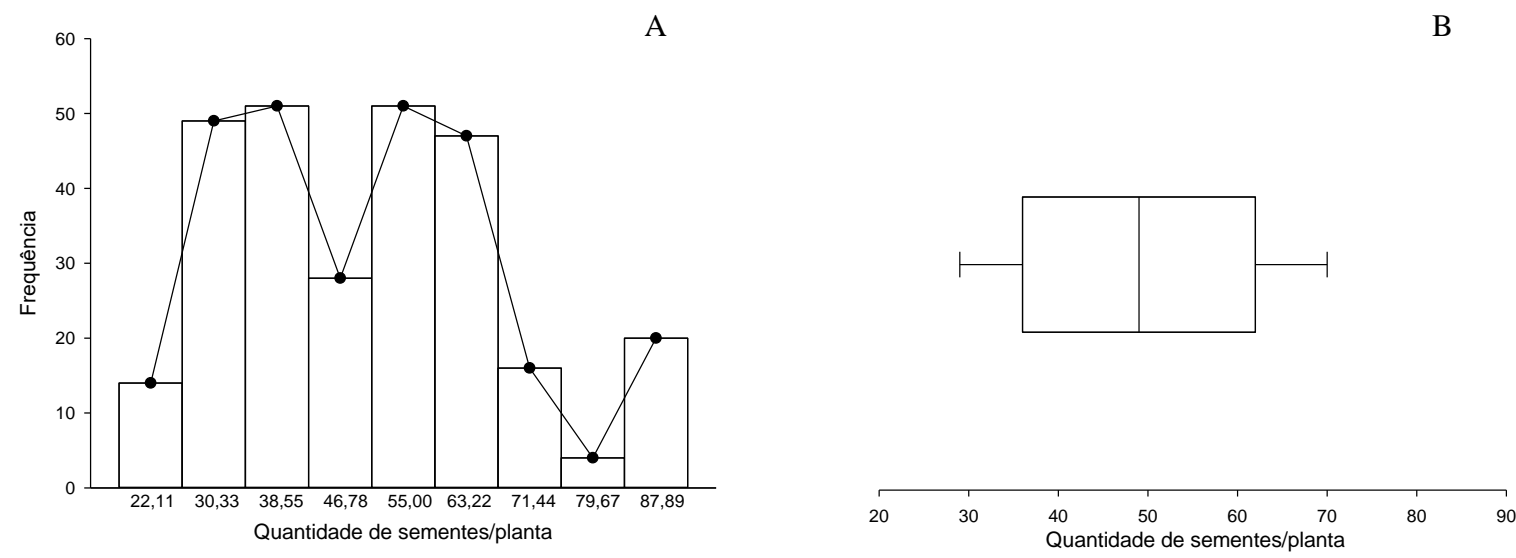

Fonte: Autores (2020).

A produção de sementes/planta manifestou distribuição unimodal e assimetria à direita, o pico no ponto médio apresentou 18,97 gramas (Figura 21A). Os valores para o resumo dos cincos pontos foram de 12,92 g (menor valor), $18,39 \mathrm{~g}$ $\left(\mathrm{Q}_{1}\right), 26,36 \mathrm{~g}\left(\mathrm{Q}_{2}\right), 34,41 \mathrm{~g}\left(\mathrm{Q}_{3}\right)$ e 49,75 $\mathrm{g}$ (maior valor) (Figura 21B). Os valores da média foram de 26,75 g, da mediana igual $26,35 \mathrm{~g}$, do desvio padrão $9,53 \mathrm{~g}$ e do coeficiente de variação $35,63 \%$.

Figura 21 - Histograma, polígono de frequência (A) e boxplot (B) da produção de semente/planta de 70 variedades de Phaseolus lunatus. Umirim-CE, 2017.

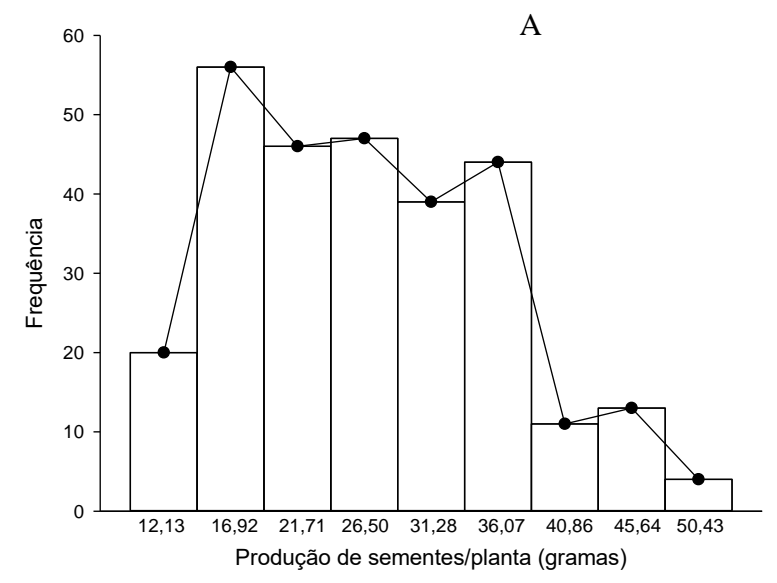

Fonte: Autores (2020).

A partir da análise das estatísticas descritivas apresentadas anteriormente sobre as informações geradas na biometria das sementes e plantas das variedades de fava foi possível apresentar os seguintes descritores com suas classificações para auxiliar na caracterização agromorfológica e na divergência genética. Para utilização das informações das tabelas procede-se inicialmente com aferição dos parâmetros a serem avaliados (comprimento, largura, espessura, peso, quantidade e tempo). Em seguida, localize-se no parâmetro que se deseja o intervalo que contempla o valor aferido para esta, obtendo-se assim, a classe (Coluna 1), informação quantitativa que pode ser utilizado na divergência genética, e a classificação (Coluna 2), informação qualitativa que auxilia na descrição. Segue as tabelas: 
Tabela 3 - Classificação das medidas das sementes de 70 variedades de Phaseolus lunatus. Umirim-CE, 2017.

\begin{tabular}{ccccc}
\hline \multirow{2}{*}{ Classes } & Classificação & \multicolumn{3}{c}{ Semente $(\mathbf{m m})$} \\
\cline { 2 - 5 } & & Comprimento & Largura & Espessura \\
\hline 1 & Extrapequeno & $<10,98$ & $<8,03$ & $<4,89$ \\
2 & Pequeno intermediário & $10,98-12,03$ & $8,03-8,60$ & $4,89-5,17$ \\
3 & Pequeno & $12,03-13,08$ & $8,03-9,18$ & $5,17-5,46$ \\
4 & Médio-pequeno & $13,08-14,12$ & $9,18-9,76$ & $5,46-5,74$ \\
5 & Médio & $14,12-15,17$ & $9,76-10,34$ & $5,74-6,02$ \\
6 & Médio-grande & $15,17-16,22$ & $10,34-10,91$ & $6,02-6,31$ \\
7 & Grande & $16,22-17,26$ & $10,91-11,49$ & $6,31-6,59$ \\
8 & Grande intermediário & $17,26-18,31$ & $11,49-12,07$ & $6,59-6,87$ \\
9 & Extragrande & $>18,31$ & $>12,07$ & $>6,87$ \\
\hline
\end{tabular}

Fonte: Autores (2020).

Tabela 4 - Classificação do peso de mil sementes de 70 variedades de Phaseolus lunatus. Umirim-CE, 2017.

\begin{tabular}{ccc}
\hline Classes & Classificação & Peso de mil sementes (g) \\
\hline 1 & Muito baixo & $<241,54$ \\
2 & Baixo intermediário & $241,54-314,43$ \\
3 & Baixo & $314,43-387,32$ \\
4 & Médio-baixo & $387,32-460,21$ \\
5 & Médio & $460,21-533,10$ \\
6 & Médio-alto & $533,10-606,00$ \\
7 & Alto & $606,00-678,88$ \\
8 & Alto intermediário & $678,88-751,77$ \\
9 & Muito alto & $>751,77$ \\
\hline
\end{tabular}

Fonte: Autores (2020). 
Tabela 5 - Classificação das medidas do folíolo central de 70 variedades de Phaseolus lunatus. Umirim-CE, 2017.

\begin{tabular}{cccc}
\hline \multirow{2}{*}{ Classes } & Classificação & \multicolumn{2}{c}{ Folíolo central (cm) } \\
\cline { 3 - 4 } & & Comprimento & Largura \\
\hline 1 & Extrapequeno & $<2,53$ & $<2,01$ \\
2 & Pequeno intermediário & $2,53-3,60$ & $2,01-3,02$ \\
3 & Pequeno & $3,60-4,67$ & $3,02-4,03$ \\
4 & Médio-pequeno & $4,67-5,73$ & $4,03-5,04$ \\
5 & Médio & $5,73-6,80$ & $5,04-6,05$ \\
6 & Médio-grande & $6,80-7,87$ & $6,05-7,07$ \\
7 & Grande & $7,87-8,93$ & $7,07-8,08$ \\
8 & Grande intermediário & $8,93-10,00$ & $8,08-9,08$ \\
9 & Extragrande & $>10,00$ & $>9,08$ \\
\hline
\end{tabular}

Fonte: Autores (2020).

Tabela 6 - Classificação do tempo até a floração de 70 variedades de Phaseolus lunatus. Umirim-CE, 2017.

\begin{tabular}{ccc}
\hline Classes & Classificação & Tempo até a floração (dias) \\
\hline 1 & Extraprecoce & $\leq 50,11$ \\
2 & Precoce intermediária & $50,11-58,33$ \\
3 & Precoce & $58,33-66,56$ \\
4 & Média precoce & $66,56-74,78$ \\
5 & Média & $74,78-83,00$ \\
6 & Média tardia & $83,00-91,22$ \\
7 & Tardia & $91,22-99,44$ \\
8 & Tardia intermediária & $99,44-107,67$ \\
9 & Extragrande & $>107,67$ \\
\hline
\end{tabular}

Fonte: Autores (2020).

Tabela 7 - Classificação do tamanho do botão floral de 70 variedades de Phaseolus lunatus. Umirim-CE, 2017.

\begin{tabular}{ccc}
\hline Classes & Classificação & Tamanho do botão floral $(\mathbf{m m})$ \\
\hline 1 & Extrapequeno & $<4,56$ \\
2 & Pequeno intermediário & $4,56-4,97$ \\
3 & Pequeno & $4,97-5,38$ \\
4 & Médio-pequeno & $5,38-5,79$ \\
5 & Médio & $5,79-6,20$ \\
6 & Médio-grande & $6,20-6,61$ \\
7 & Grande & $6,61-7,02$ \\
8 & Grande intermediário & $7,02-7,43$ \\
9 & Extragrande & $>7,43$ \\
\hline
\end{tabular}


Tabela 8 - Classificação das medidas da vagem de 70 variedades de Phaseolus lunatus. Umirim-CE, 2017.

\begin{tabular}{ccccc}
\hline \multirow{2}{*}{ Classes } & Classificação & \multicolumn{3}{c}{ Vagem $(\mathbf{c m})$} \\
\cline { 3 - 4 } & & Comprimento & Largura & Espessura \\
\hline 1 & Extrapequeno & $<5,41$ & $<0,70$ & $<0,25$ \\
2 & Pequeno intermediário & $5,41-5,81$ & $0,70-0,90$ & $0,25-0,35$ \\
3 & Pequeno & $5,81-6,20$ & $0,90-1,10$ & $0,35-0,45$ \\
4 & Médio-pequeno & $6,20-6,59$ & $1,10-1,30$ & $0,45-0,55$ \\
5 & Médio & $6,59-6,98$ & $1,30-1,50$ & $0,55-0,65$ \\
6 & Médio-grande & $6,98-7,37$ & $1,50-1,70$ & $0,65-0,75$ \\
7 & Grande & $7,37-7,76$ & $1,70-1,90$ & $0,75-0,85$ \\
8 & Grande intermediário & $7,76-8,15$ & $1,90-2,10$ & $0,85-0,95$ \\
9 & Extragrande & $>8,15$ & $>2,10$ & $>0,95$ \\
\hline
\end{tabular}

Fonte: Autores (2020).

Tabela 9 - Classificação da quantidade de vagens/planta de 70 variedades de Phaseolus lunatus. Umirim-CE, 2017.

\begin{tabular}{ccc}
\hline Classes & Classificação & Quantidade de vagens/planta \\
\hline 1 & Muito baixa & $<11,39$ \\
2 & Baixa intermediária & $11,39-14,17$ \\
3 & Baixa & $14,17-16,94$ \\
4 & Média baixa & $16,94-19,72$ \\
5 & Média & $19,72-22,50$ \\
6 & Média alta & $22,50-25,28$ \\
7 & Alta & $25,28-28,06$ \\
8 & Alta intermediária & $28,06-30,83$ \\
9 & Muito alta & $>30,83$ \\
\hline
\end{tabular}

Fonte: Autores (2020).

Tabela 10 - Classificação do número de sementes/vagem de 70 variedades de Phaseolus lunatus. Umirim-CE, 2017.

\begin{tabular}{ccc}
\hline Classes & Classificação & Número de sementes/vagem \\
\hline 1 & Muito baixa & $<1,99$ \\
2 & Baixa intermediária & $1,99-2,14$ \\
3 & Baixa & $2,14-2,29$ \\
4 & Média baixa & $2,29-2,44$ \\
5 & Média & $2,44-2,58$ \\
6 & Média alta & $2,58-2,73$ \\
7 & Alta & $2,73-2,88$ \\
8 & Alta intermediária & $2,88-3,03$ \\
9 & Muito alta & $>3,03$ \\
\hline
\end{tabular}

Fonte: Autores (2020). 
Tabela 11 - Classificação da quantidade de sementes/planta de 70 variedades de Phaseolus lunatus. Umirim-CE, 2017.

\begin{tabular}{ccc}
\hline Classes & Classificação & Quantidade de sementes/planta \\
\hline 1 & Muito baixa & $<22,11$ \\
2 & Baixa intermediária & $22,11-30,33$ \\
3 & Baixa & $30,33-38,55$ \\
4 & Média baixa & $38,55-46,78$ \\
5 & Média & $46,78-55,00$ \\
6 & Média alta & $55,00-63,22$ \\
7 & Alta & $63,22-71,44$ \\
8 & Alta intermediária & $71,44-79,67$ \\
9 & Muito alta & $>79,67$ \\
\hline
\end{tabular}

Fonte: Autores (2020).

Tabela 12 - Classificação da produção de sementes/planta de 70 variedades de Phaseolus lunatus. Umirim-CE, 2017.

\begin{tabular}{ccc}
\hline Classes & Classificação & Produção de sementes/planta $(\mathbf{g})$ \\
\hline 1 & Muito baixa & $<12,13$ \\
2 & Baixa intermediária & $12,13-16,92$ \\
3 & Baixa & $16,92-21,71$ \\
4 & Média baixa & $21,71-26,50$ \\
5 & Média & $26,50-31,28$ \\
6 & Média alta & $31,28-36,07$ \\
7 & Alta & $36,07-40,86$ \\
8 & Alta intermediária & $40,86-45,64$ \\
9 & Muito alta & $>45,64$ \\
\hline
\end{tabular}

Fonte: Autores (2020).

\section{Discussão}

Os resultados da biometria das sementes foram semelhantes ao estudo de Guimarães et al. (2007), com 14 acessos de favas da Coleção de Germoplasma da Universidade Federal Rural do Pernambuco. Os valores das medidas das sementes variaram de 11,30 a 16,90 mm no comprimento, de 7,40 a 11,70 mm na largura e de 4,30 a 6,10 mm na espessura, estando estas dimensões compreendidas nos intervalos de valores da presente pesquisa. Geralmente, as medidas das sementes correlacionamse positivamente com o peso da semente, como se observa nos trabalhos de Advíncula et al. (2015), Nobre et al. (2012) e Santos et al. (2002), em que os genótipos que apresentaram as maiores medidas obtiveram os maiores valores para peso de 1000 sementes.

Das relações entre as medidas aferidas na semente resulta a forma e o perfil desta semente, características valorosas, para exploração da preferência do consumidor e para futuros processos de beneficiamento dos grãos. Advíncula et al. (2015) observaram que as sementes adquiridas no mercado municipal de Montes Claros/MG apresentavam as formas esféricas e elípticas, e os perfis achatado, semicheio ou cheio. Na pesquisa de Santos et al. (2002) as sementes foram adquiridas em feiras livres de municípios das regiões de Curimataú Oriental e Brejo Paraibano, no estado da Paraíba, apresentavam em sua maioria formas esféricas e elípticas, mas com perfis achatados ou cheios, sendo ainda constatada uma variedade com forma oblonga e 
perfil cheio.

$\mathrm{Na}$ característica peso de 1000 sementes, observou-se nesta pesquisa valores entre 241,54 a 824,66 gramas, o que equivaleria a uma variação de 1.213 a 4.140 sementes $/ \mathrm{kg}$, respectivamente. Em variedades de fava coletadas em Minas Gerais, Nobre et al. (2012) perceberam oscilações entre 316,86 a 932,08 gramas, alcançando a variação de 1.073 a 3.156 sementes $/ \mathrm{kg}$. O peso das sementes representam uma das características mais relevantes do ponto de vista do desenvolvimento fisiológico da cultura, pois sementes maiores e mais pesadas apresentam maiores teores de reserva que proporcionam maior porcentagem de emergência de plântulas em campo (Advíncula et al., 2015), além de produzirem mais nódulos nas raízes que proporcionam maior massa foliar (matéria seca) da parte aérea devido a maior fixação de nitrogênio atmosférico (Dobert \& Blevins, 1993) proporcionando maiores produtividades. Assim, o peso das sementes torna-se um dos melhores indicativos de rendimento em fava, indicado como critério de seleção por apresentar uma maior herdabilidade no sentido amplo (Akande \& Balogun, 2007).

Com relação as cores do tegumento da semente, as favas apresentam uma grande variação, seja em uma única cor ou nos conjuntos formados com manchas, estrias ou pontuações de outras cores espalhadas pela semente. Na pesquisa de Nobre et al. (2012) foram observadas sementes com cor principal branca, branca rosada, bruno-forte, rosada, cinzenta-rosada e preta. Enquanto, na cor secundária manchas preto-avermelhadas, vermelho-acinzentadas e vermelha-escuras, além de algumas com estrias bruno-avermelhado-claro e branca. Nas cores das variedades de fava trabalhadas por Silva et al. (2015) os resultados não foram diferentes, estando presentes sementes com coloração branca, bege, amarela, laranja, verde, marrom e preta, além de algumas destas com mancha preta ou marrom ao redor do hilo.

Logo, a cor do tegumento possui importância botânica, por auxiliar a diferenciação entre os genótipos, mas também esta característica detém um carácter comercial, podendo atuar favoravelmente ou não na comercialização do produto, o que dependerá da preferência dos consumidores nas diferentes regiões do país. No Chile, Vera, Paredes e Becerra (1999) conseguiram diferenciar as classes comerciais de feijões (Phaseolus vulgaris L.) a partir das cores de seus grãos. No Brasil, o Ministério da Agricultura, Pecuária e Abastecimento (MAPA) atendendo as exigências do mercado de grãos e sementes de feijão-caupi (Vigna unguiculata) criou padrões para classificação (Grupos, Classes e Tipos) baseada principalmente na cor do tegumento e em suas variações (BRASIL, 2009), medidas que futuramente poderão ser tomadas para padronização de sementes e grãos de fava.

Quanto às características da planta, de acordo com as observações realizadas foi verificado a presença de plântulas com cotilédones nas cores verde ou púrpura, enquanto que no hipocótilo observou-se a presença das cores verde, púrpura e uma baixa quantidade na cor vermelho-púrpura. Estas colorações seguem a mesma predominância das encontradas em variedades da Paraíba, nos trabalhos de Frazão et al. (2010) e Medeiros et al. (2015). Segundo Frazão et al. (2010) a cor dos cotilédones e hipocótilo estão correlacionados com a cor da flor e que estas informações podem auxiliar na identificação de genótipos de fava.

Nas medidas de comprimento e largura do folíolo central os achados foram similares aos de López-Alcocer et al. (2016) que observou variações de 3,78 a 10,70 cm no comprimento e de 2,16 a 5,18 cm na largura. Ao comparar os dados desses trabalhos com os valores constatados por Frazão et al. (2010), verificou-se também que havia a mesma semelhança entre os dados. Estes pesquisadores verificaram ainda que as variedades por eles trabalhadas possuíam representantes com folíolos centrais nas formas redondas, ovais e ovais-lanceoladas. Enquanto a forma do folíolo possui interesse para diferenciação entre genótipos, as medidas dos folíolos apresenta aplicabilidade na determinação do índice de área foliar (IAF) da planta, indicativo de potencial produtivo (Lopes \& Lima, 2015).

Os valores encontrados para o tamanho do botão floral se assemelharam aos achados por Melo (2011), que em estudo com 26 acessos de favas procedentes de diversas localidades do Brasil, observou que os tamanhos dos botões florais estavam compreendidos entre 6,47 a 7,71 mm de comprimento. Também eram compatíveis com os das variedades de fava trabalhadas por Frazão et al. (2010) que apresentaram tamanhos de 5,00 a 6,00 mm de comprimento, com média de 5,63 mm.

Para o tempo até a floração verificou-se uma média de 82,50 dias, contra 72 dias constatados por Santos et al. (2002) 
em estudo com 8 variedades de fava da Paraíba e 95,87 dias verificados por Silva et al. (2017) em 166 acessos do Banco de Germoplasma da Embrapa Recursos Genéticos. No entanto, maiores semelhanças foram encontradas nos valores de 55 a 107 dias e média 87,25 dias obtidos no estudo de Oliveira, Torres e Benedito (2011) em variedades de fava de pequenos produtores do Rio Grande do Norte. Os resultados obtidos com essa característica permite, a compreensão das respostas ambientais, a condução das escolhas das épocas e locais de plantio mais adequados, a otimização das colheitas e a disponibilidade do produto em função das necessidades e demandas do mercado consumidor (Vaz; Santos \& Zaidan, 2004).

$\mathrm{Na}$ análise das cores de partes das flores (asas, estandarte e quilha), Frazão et al. (2010) verificaram que as flores, em sua maioria, apresentavam a cor branca para asas e estandarte e a cor esverdeada para quilha, diferindo do estudo em questão apenas quanto a coloração do estandarte, que apresentou predominantemente cor verde-amarelado. Esta cor inclusive, foi adicionada as possíveis cores que podem ser encontradas nas partes florais de variedades de fava.

A quantidade de vagens/planta encontradas por Silva et al. (2015) variaram de 4,26 até 16,05 vagens, tendo atingido média geral de 8,7 vagens/planta. Enquanto que as quantidades da pesquisa de Oliveira, Torres \& Benedito (2011) ficaram entre 19 e 54 vagens, com média de 34,50 vagens/planta. Estes resultados diferem e muito daqueles encontrados na pesquisa em questão que obteve dados intermediários, com média de 18,97 vagens/planta. Esta é uma das características genéticas importantes na identificação de genótipos potencialmente produtivos, ainda mais quando está associada as características número de sementes/vagem e peso das sementes.

$\mathrm{Na}$ classificação da vagem quanto a forma do ápice e curvatura, destacaram-se vagens com ápices curtos ou grossos e com curvaturas, direta, ligeiramente curva e curva. Enquanto que Vera et al. (2015) encontraram vagens com ápices médios ou longos e curvatura curva ou ligeiramente curva em variedades de fava peruanas. Estas características tem natureza apenas descritivas, mas vagens sem a presença de acúleo no ápice seria ideal por facilitar a colheita manual.

Quanto as medidas das vagens, as variedades de fava avaliadas por Guimarães et al. (2007) apresentaram medidas bem próximas as observadas nesta pesquisa, para comprimento a medida foi de 4,86 a 8,95 cm, para largura de 1,39 a 2,14 cm e espessura de 0,1 a 0,79 cm. Em Silva et al. (2015) os valores também são semelhantes. Para o comprimento das vagens a medida encontrada foi de 4,95 a 9,98 cm e a largura de 1,24 a 1,76 cm. As médias das vagens também foram correspondentes as aferidas por Silva et al. (2017), sendo 6,43 cm para comprimento e 1,45 cm para largura. Maiores medidas das dimensões das vagens são indicativos de genótipos mais produtivos, pois representa a capacidade da vagem de comportar número maior de sementes e/ou de sementes mais pesadas, como se verifica nas pesquisas de Santos et al. (2002) e Barreiro Neto et al. (2015).

Outra característica de importância produtiva é a quantidade de sementes/vagem. Nas variedades avaliadas por Guimarães et al. (2007) a quantidade de sementes/vagem estavam em conformidade com a pesquisa em questão, com exceção de uma das variedades que apresentou de duas a seis sementes/vagem. Nos estudo de López-Alcocer et al. (2016) foram verificados valores de intervalos maiores, com variedades apresentando médias de 1,30 a 4,60 sementes/vagem.

As características quantidade de sementes/planta e produção de semente/planta foram introduzidas com intuito de estimar a produção individual. Estas informações podem ser facilmente extrapoladas utilizando o espaçamento adotado para cultura com o número de planta possíveis na área, tendo assim uma previsão de produtividade. Portanto, são variáveis balizadoras para tomadas de decisão.

Ao longo desse estudo foi possível perceber a alta variabilidade genética encontrada em P. lunatus. As classificações apresentadas nas tabelas permitem quantificar características (principalmente de importância produtiva) que até então, não estavam incluídas nas avaliações de germoplasma da cultura. As contribuições, portanto, possibilitam os estudos de beneficiamento de sementes e grãos, investigação da preferência do consumidor e as pesquisas de divergência genética. Estas informações devem ser implementadas aos descritores de P. lunatus. 


\section{Conclusão}

As variedades de fava apresentaram alta variabilidade genética.

As características da semente (cor do tegumento, comprimento, largura, espessura e peso de 1000 sementes) são valorosas para, escolha de genótipos produtivos, exploração da preferência do consumidor e em futuros processos de padronização e beneficiamento dos grãos.

As características da planta (tamanho do botão floral, comprimento, largura e espessura da vagem, número de sementes/vagem, quantidade de sementes/planta e produção de sementes/planta) por sua vez são relevantes para escolha de genótipos promissores em produtividade.

Estas informações devem ser incorporadas aos descritores de Phaseolus lunatus para subsidiar futuras pesquisas afim de possibilitar reconhecer as características de identidade, distinguibilidade e estabilidade genética, além de proporcionar base para os estudos de divergência genética.

\section{Referências}

Advíncula, T. L., Nadai, F. B., Nobre, D. A. C., Ferreira, E. N. M. B., Brandão Júnior, D. S. \& Costa, C. A. (2015). Qualidade física e fisiológica de sementes de Phaseolus lunatus L. Revista Brasileira de Ciências Agrárias, 10 (3), 341-346. 10.5039/agraria.v10i3a2548.

Akande, S. R. \& Balogun, M. O. (2007). Evaluation and heritability studies of local Lima bean (Phaseolus lunatus L.) cultivars from south-west Nigeria. Revista Cientifica UDO Agrícola, 7 (1), 22-28. https://dialnet.unirioja.es/servlet/articulo?codigo=2550640.

Azevedo, J. N., Franco, L. J. D., Araújo, R. O. C. (2003). Composição química de sete variedades de feijão-fava. Embrapa Meio-Norte, Teresina, PI. https://www.infoteca.cnptia.embrapa.br/bitstream/doc/66292/1/CT152.pdf.

Barreiro Neto, M., Fagundes, R. A. A., Barbosa, M. M.; Arriel, N. H. C., Franco, C. F. O. \& Santos, J. F. (2015). Características morfológicas e produtivas em acessos de feijão-fava consorciados. Tecnologia e Ciência Agropecuária, 9 (3), 23-27. https://revistatca.pb.gov.br/edicoes/volume-09-2015/volume-9-numero3-junho-2015/fitotecnia-crop-science/tca9305.pdf.

Brasil. (2009). Regras para análise de sementes. Brasília: MAPA, 2009. https://www.gov.br/agricultura/pt-br/assuntos/insumos-agropecuarios/arquivospublicacoes-insumos/2946_regras_analise_sementes.pdf.

Dobert, R. C. \& Blevins, D. G. (1993). Effect of seed size and plant growth on nodulation and nodule development in lima bean (Phaseolus lunatus L.). Plant and Soil, 148 (1), 11-19. https://link.springer.com/article/10.1007/BF02185380.

Frazão, J. E. M., Santos, D., Oliveira, F. P., Pereira, W. S. \& Morais, J. F. (2010). Morfologia e fenologia de dez variedades de fava nas fases vegetativas e de inflorescência. Agropecuária Técnica, 31 (1), 18-24. https://periodicos.ufpb.br/index.php/at/article/view/3722.

Gonçalves, L. G. V., Andrade, F. R., Marimon Júnior, B. H., Shossler, T. R., Lenza, E. \& Marimon, B. S. (2013). Biometria de frutos e sementes de mangaba (Hancornia speciosa Gomes) em vegetação natural na região leste de Mato Grosso, Brasil. Revista de Ciências Agrárias, 36 (1), 31-40. http://www.scielo.mec.pt/scielo.php?script=sci_arttext\&pid=S0871-018X2013000100006.

Guimarães, W. N. R., Martins, L. S. S., Silva, E. F., Ferraz, G. M. G. \& Oliveira, F. J. (2007). Caracterização morfológica e molecular de acessos de feijão-fava (Phaseolus lunatus L.). Revista Brasileira de Engenharia Agrícola e Ambiental, 11 (1), 37-45. https://doi.org/10.1590/S1415-43662007000100005.

IBPGR. (1982) Lima Bean Descriptors. Roma: Centro Internacional para os Recursos Genéticos Vegetais, 36 p.

IPGRI. (2001). Descritores para Phaseolus lunatus. Oeiras: International Plant Genetic Resoures Institute, 51 p. https://www.bioversityinternational.org/fileadmin/_migrated/uploads/tx_news/Descritores_para_Phaseolus_lunatus_724.pdf.

Lopes, N. F. \& Lima, M. A. G. S. (2015). Fisiologia da produção. Viçosa: UFV, 492 p.

López-Alcocer, J. J., Lépiz-Ildefonso, R., González-Eguiarte, D. R., Rodrígues-Macías, R. \& López-Alcócer, E. (2016). Variabilidad morfológica de Phaseolus lunatus L. silvestre de la refión occidente de México. Revista de Fitotecnia do México, 39 (1), 49-58. http://www.scielo.org.mx/pdf/rfm/v39n1/v39n1a9.pdf.

Macedo, M. C., Scalon, S. P. Q., Sari, A. P., Scalon Filho, H., Rosa, Y. B. C. J. \& Robaina, A. D. (2009). Biometria de frutos e sementes e germinação de Magonia pubescens St.Hil (Sapindaceae). Revista Brasileira de Sementes, 31 (2), 202-211. https://www.scielo.br/pdf/rbs/v31n2/v31n2a24.pdf.

Medeiros, V. S. S., Almeida, L. S., Paula, A. C., Marini, F. S. \& Arriel, N. H. C. (2015). Caracterização morfoagronômica de fava (Phaseolus lunatus L.). Cadernos de agroecologia. Trabalho apresentado no IX Congresso Brasileiro de Agroecologia, Belém. http://revistas.abaagroecologia.org.br/index.php/cad/article/view/18241/13173.

MELO, L. F. Divergência genética em subamostras de feijão-fava (Phaseolus lunatus L.) por meio de marcadores agromorfológicos e microssatélites. 2011. Dissertação (Mestrado em Genética e Melhoramento) - Centro de Ciências Agrárias, Universidade Federal do Piauí, Teresina.

Munsell Color. (1994). Munsell soil color charts. New Windson: Color Company, 16 p. 
Research, Society and Development, v. 10, n. 2, e1210212137, 2021

(CC BY 4.0) | ISSN 2525-3409 | DOI: http://dx.doi.org/10.33448/rsd-v10i2.12137

Nobre, D. A. C., Brandão Junior, D. S., Nobre, E. C., Santos, J. M. C., Miranda, D. G. S. \& Alves, L. P. (2012). Qualidade física, fisiológica e morfologia externa de sementes de dez variedades de feijão-fava (Phaseolus lunatus L.). Revista Brasileira de Biociências, 10 (4), 425-429. http://www.ufrgs.br/seerbio/ojs/index.php/rbb/article/view/2220/1155.

Oliveira, F. N., Torres, S. B. \& Benedito, C. P. (2011). Caracterização botânica e agronômica de acessos de feijão-fava, em Mossoró, RN. Revista Caatinga, 24 (1), 143-148. https://periodicos.ufersa.edu.br/index.php/caatinga/article/view/1936.

Pegado, C. M. A., Barbosa, L. J., Mendes, J. E. M. F., Souto, P. C. \& Souto, J. S. (2008). Decomposição superficial e subsuperficial de folhas de fava (Phaseolus lunatus L.) na região do brejo da Paraíba. Revista Caatinga, 21 (1), 218-223. https://www.redalyc.org/pdf/2371/237117576031.pdf.

Ramos, S. R. R. \& Queiróz, M. A. (1999). Caracterização morfológica: experiência no BAG de cucurbitáceas da Embrapa Semi-Árido, com acessos de abóbora e moranga. Horticultura Brasileira, 17, 9-12. https://www.alice.cnptia.embrapa.br/handle/doc/133835.

Santos, D., Corlett, F. M. F., Mendes, J. E. M. F. \& Wanderley Júnior, J. S. A. (2002). Produtividade e morfologia de vagens e sementes de variedades de fava no Estado da Paraíba. Pesquisa Agropecuária Brasileira, 37 (10), 1407-1412. https://www.scielo.br/pdf/pab/v37n10/13219.pdf.

Santos, R. D., Lemos, R. C., Santos, H. G., Ker, J. C. \& Anjos, L. H. C. (2005). Manual de descrição e coleta de solo no campo. $5^{\text {a }}$ ed. Viçosa: Sociedade Brasileira de Ciência de Solo, $92 \mathrm{p}$.

Santos, H. G. Jacomine, P. K. T., Anjos, L. H. C., Oliveira, V. A., Lumbreras, J. F., Coelho, M. R., Almeida, J. A., Cunha, T. J. F.\& Oliveira, J. B. (2013). Sistema brasileiro de classificação de solos. $5^{\mathrm{a}}$ ed. Brasília: Embrapa, 365 p.

Silva, R. N. O., Burle, M. L., Pádua, J. G., Lopes, A. C. A., Gomes, R. L. F. \& Martínez-Castillo, J. (2017). Phenotypic diversity in lima bean landraces cultivated in Brazil, using the Ward-MLM strategy. Chilean Journal of Agricultural Research, 77 (1), 35-40. http://dx.doi.org/10.4067/S0718-58392017000100004.

Silva, V. B., Gomes, R. L. F., Lopes, A. C. A., Dias, C. T. S. \& Silva, R. N. O. (2015). Genetic diversity and promising crosses indication in lima bean (Phaseolus lunatus) accessions. Semina: Ciências Agrárias, 36 (2), 683-692. DOI: 10.5433/1679-0359.2015v36n2p683.

Vaz, A. P. A., Santos, H. P. \& Zaidan, L. B. P. (2004). Floração. In: Kerbauy, G. B. Fisiologia Vegetal. Editora Guanabara, 470p.

Vera, C. M., Paredes, M. C. \& Becerra, V. V. (1999). Estudio comparativo de diversidad morfológica, isoenzimatica y RAPDs dentro y entre clases comerciales de frijol chileno (Phaseolus vulgaris L.). Agricultura Técnica, 59 (4), 247-259.

Vera, M. F. P., Alcántara, E. L., Araujo, E. C. \& Soto, J. C. R. (2015). Variabilidad morfo-agronómica en poblaciones de pallar, Phaseolus lunatus, cultivado en condiciones de Costa de la Provincia de Trujillo (Perú). Revista Científica de la Facultad de Ciencias Biológicas, 35 (2), $29-38$. https://revistas.unitru.edu.pe/index.php/facccbiol/article/view/1073/1001.

Vieira, C. Leguminosas de grãos: importância econômica na agricultura e alimentação humana. Informe Agropecuário, Belo Horizonte, Informe Agropecuário, 1992. http://www.scielo.br/scielo.php?script=sci_nlinks\&ref=000072\&pid=S0100-204X200200100000800009\&lng=en.

Vilhordo, B. W., Mikusinski, O. M. F., Burin, M. E., Gandolfi, V. H. Morfologia. In: Araújo, R. S., Rava, C. A., Stone, L. F., Zimmermann, M. J. O. Cultura do feijoeiro comum no Brasil. Piracicaba: Potafos, 1996. 71-99. 